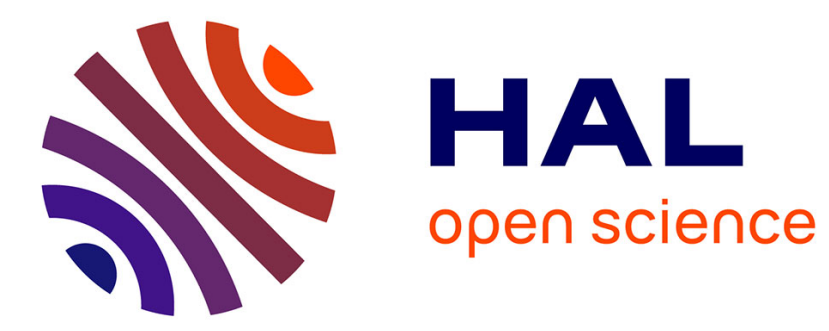

\title{
Incremental gravimetry: a method for two-parameter model building of binary gas adsorption equilibria
}

Daniel Tondeur, Karine Bonnot, Ling-Ai Luo

\section{To cite this version:}

Daniel Tondeur, Karine Bonnot, Ling-Ai Luo. Incremental gravimetry: a method for two-parameter model building of binary gas adsorption equilibria. Adsorption - Journal of the International Adsorption Society, 2004, 10 (2), pp.159-185. 10.1023/B:ADSO.0000039871.54178.1b . hal-00785320

\section{HAL Id: hal-00785320 \\ https://hal.science/hal-00785320}

Submitted on 6 Feb 2013

HAL is a multi-disciplinary open access archive for the deposit and dissemination of scientific research documents, whether they are published or not. The documents may come from teaching and research institutions in France or abroad, or from public or private research centers.
L'archive ouverte pluridisciplinaire HAL, est destinée au dépôt et à la diffusion de documents scientifiques de niveau recherche, publiés ou non, émanant des établissements d'enseignement et de recherche français ou étrangers, des laboratoires publics ou privés. 


\title{
INCREMENTAL GRAVIMETRY: \\ A METHOD FOR TWO-PARAMETER MODEL BUILDING \\ OF BINARY GAS CO-ADSORPTION EQUILIBRIA
}

\author{
D. TONDEUR*, K. BONNOT, L. LUO, \\ Laboratoire des Sciences du Génie Chimique-CNRS \\ ENSIC-INPL Nancy, France \\ * corresponding author, tondeur@ensic.inpl-nancy.fr
}

\begin{abstract}
This paper presents and develops a novel methodology to determine thermodynamic parameters of binary gas co-adsorption equilibria at given total pressure, based exclusively on binary gravimetric measurements at this same total pressure, together with single component isotherms. By "Incremental Gravimetry", we designate a procedure in which the adsorbent sample is submitted to increments of composition of a flowing binary gas, and the corresponding increments of weight of the sample at equilibrium are measured. The experimental example is the co-adsorption of methane and carbon dioxide on Norit activated carbon near ambient temperature and pressure.

The approach relies on the thermodynamics of non-ideal adsorbed solutions. The experimental methodology is described, the underlying theory is then presented. Compact analytical expressions are established that relate the measured limiting slopes of the incremental gravimetric curves (at infinite dilution of one component in the other) to quantities that derive only from the pure component isotherms, and to the infinite dilution activity coefficients. The latter are then uniquely determined. Classical two-parameter models for the composition dependence of activity coefficients are then implemented to reconstruct the complete binary isotherms and the incremental gravimetric curves. The comparison of the latter with the measured curves permits to test the different models.
\end{abstract}




\section{INTRODUCTION}

The present work was motivated by the need for a predictive approach to multicomponent adsorptive equilibria (multi- meaning more than two) in the simulation of gas purification processes. The most classical approaches, for vapour-liquid equilibrium for example, rely on the multi-component extension of binary properties. In such a framework, it is in principle sufficient to measure single component properties and some characteristic binary quantities, and then to incorporate these data into a coherent and possibly general thermodynamic model suitable for multi-component extension. The present work was therefore oriented toward the building of the theoretical model directly and simultaneously with an experimentally simple measurement, and the use of a theoretical framework that allows extension to multicomponent systems from binaries.

Microbalance weight measurement is a classical technique for the determination of single component gas phase adsorption isotherms. The weight change of the adsorbent sample gives directly the increment in adsorbed quantity corresponding to an applied change in partial pressure of the adsorbed species. The convenience and precision of the weight measurements motivate the extension of their principle to mixture adsorption. However, when more than one component is adsorbed, the weight variation alone does not a priori furnish enough information to discriminate between the different components. The most direct approach is then to desorb the adsorbed components into an evacuated container and to analyse the content, thus obtaining a direct information on the adsorbed phase composition. This procedure is heavy and not necessarily accurate. A classical alternative [Do, 1998] is to simultaneously measure the composition variation of the gas phase in a batch equilibration process, and to retrieve the adsorbed quantities of each component from a materiel balance over the equilibration process. However simple this procedure appears, it introduces imprecision due to the sampling and analysis of the gas phase and of course, it requires time and investment for the analytical device. Powerful alternatives have been developed by Keller and co-workers, based on measuring simultaneously the mass adsorbed and the density of the gas phase, or on simultaneous gravimetric and volumetric measurements [Keller et al., 1999; Dreisbach et al.,2001]. In these procedures, the chemical analysis of the gas phase is replaced by an additional physical measurement, which may be automated.

All the preceding methods are direct measurements independent of any model, and even of any thermodynamic assumption. If modelling for simulation is the goal, some postulated models have to be fitted to the results thus obtained, and the choice of models and of fitting method is left open. A different philosophy of approach arises when one assumes that the adsorbed phase actually behaves like a macroscopic phase, and thus satisfies thermodynamic constraints, such as the Gibbs adsorption isotherm and the Gibbs-Duhem constraint. These constraints are in principle sufficient to render the measurement of the adsorbed phase composition unnecessary.

Such an approach was proposed by Van Ness [1969] to obtain the adsorbed phase composition, together with the spreading pressure, from information on the total adsorbed amount at different total pressures, using an iterative numerical calculation. Although this method is consistent and saves a considerable amount of time and equipment, it has been little used so far, may be because it is considered as a model dependent fitting method, that may lead to equivocal results. Actually, the only model 
assumptions involved in this approach are that of the Gibbs isotherm, applying classical thermodynamics to the gas/adsorbed phase equilibrium. While this approach may be inappropriate when the adsorbate does not really form a "phase", or when steric effects arise, as in the cages of zeolites, it can be reasonably and widely used and is the background of all approaches based on the Adsorbed Solution Theory [Myers and Prausnitz, 1965]. Using the Van Ness method, Van der Vaart [Van der Vaart et al., 2000] determined binary co-adsorption isotherms of methane and carbon dioxide on activated carbon Norit RB1, and we shall use an almost identical system here (with Norit RB2 instead). The same gas mixture was investigated using the same approach by [Buss, 1995] with another carbon. A few other references are to be found [Friederich and Mullins, 1972; Myers et al., 1982] with different systems.

A similar approach, also based on gravimetric measurements at different pressures but with a different numerical solution, was proposed by Myers [Myers, 1989]. He mentions that about 100 experimental points are required for a good precision, and subsequently proposes a method that requires less data, but involves an explicit model for the excess Gibbs energy as a function of composition and spreading pressure. The three parameters of this model are found by minimization of the deviation of the experimental and calculated total adsorbed mass. This method furnishes the parameters of a model together with the composition of the adsorbed phase, it is therefore not a direct measurement, but rather what we call a model-building approach. It showed excellent results for systems involving $\mathrm{CO}_{2}, \mathrm{C}_{3} \mathrm{H}_{8}$ and $\mathrm{H}_{2} \mathrm{~S}$ on $\mathrm{H}$-mordenite.

The present paper proposes an alternative approach, based on the same experimental instrument (weight measurements), and the same thermodynamic premises (the Adsorbed Solution Theory) but with a different methodology. The difference with the above approaches is that it seeks to avoid parameter fitting and optimization, and to have instead univocal algebraic determinations of the thermodynamic parameters which are the infinite dilution activity coefficients. In addition, measurements at different pressures are not needed for a given isotherm. As in Myers' approach, the adsorbed phase composition are obtained indirectly. The method partly relies on a detailed thermodynamic analysis developed for chromatographic experiments and presented in a previous publication related to chromatography [Kabir et al., 1998]. In contrast to the Van Ness approach, the thermodynamic equations are treated analytically, and no iterative numerical resolution is needed.

Let us first briefly summarize Van Ness' method as presented by [Van der Vaart, 2000]. It starts from a particular form of the Gibbs adsorption isotherm which is written at constant $\mathrm{T}$ :

$$
-\frac{1}{q_{t}} d \psi+d \ln P+\sum x_{i} d \ln y_{i}=0
$$

where $x_{i}$ and $y_{i}$ are respectively the adsorbed phase and the gas phase mole fractions, $q_{t}$ is the total adsorbed concentration [moles adsorbed $\mathrm{kg}^{-1}$ of adsorbent], $\mathrm{P}$ is total pressure, and $\psi$ is a quantity called "loading" by Myers, because it has dimensions of [moles.kg ${ }^{-1}$ ], and called "compressibility factor" by Van Ness, because it is related to the spreading pressure $\Pi$ by a relation analogous to a state equation for gases: 


$$
\psi=\frac{\Pi A}{R T}
$$

where $\mathrm{A}$ is the specific surface of the adsorbent $\left[\mathrm{m}^{2} \mathrm{~kg}^{-1}\right]$. At constant composition and $\mathrm{T}$, Equation 1 yields a relation between loading and pressure:

$$
\left(\frac{\partial \psi}{\partial P}\right)_{T, y}=\frac{q_{t}}{P}
$$

which is integrated into:

$$
\psi=\int_{0}^{P} \frac{q_{t}}{P} d P
$$

We relate $\mathrm{q}_{\mathrm{t}}$ to the total adsorbed mass $\mathrm{m}_{\mathrm{t}}$, equal to the mass $\mathrm{w}$ given experimentally by the balance minus the mass $m_{a}$ of the clean adsorbent sample. Using the average molar mass of the mixture $\mathrm{M}$ :

$$
M=\sum x_{i} M_{i}
$$

the following relation holds between these quantities:

$$
q_{t}=\frac{m_{t}}{M \cdot m_{a}}
$$

At constant $\mathrm{P}$ and $\mathrm{T}$, Equation 1 yields a relation between loading and composition:

$$
-\frac{1}{q_{t}} d \psi+\sum \frac{\mathrm{x}_{\mathrm{i}}}{\mathrm{y}_{\mathrm{i}}} d y_{i}=0
$$

or for a binary case:

$$
x=y+\frac{M y(1-y)}{m_{t}}\left(\frac{\partial \psi}{\partial y}\right)_{P, T}
$$

For a given gas phase composition y, Equations 4, 5, 6 and 8 are solved simultaneously by an iterative numerical method for the unknown variables $\psi, \mathrm{M}$ and $\mathrm{x}$. Owing to Equation 4, the experimental adsorbed mass must be determined at different total pressures for given gas compositions, between which interpolation can be performed. The method can therefore be considered as a global and thermodynamically consistent fitting method rather than a direct measurement. Once the compositions of the two phases in equilibrium are determined, they can be used to adjust an explicit model, for example to fit the parameters of an explicit binary isotherm equation, or to calculate activity coefficients in a non-ideal adsorption solution model. Notice also that the input of the single component isotherms is required only when an explicit model is to be designed. 
By contrast, the approach proposed here uses the single component isotherms as input data, and requires binary measurements only at the total pressure where the binary equilibrium is established,

\section{THE EXPERIMENTAL OPERATING MODE AND METHODOLOGY}

The experimental set-up, shown schematically on Figure 1, is basically a microthermo-balance (Rubotherm, Bochum, Germany) associated to a system for generating and circulating continuously gas or vapour mixtures. The binary compositions are adjusted using mass-flow-meters. Classically, the adsorbent sample, contained in the measuring cell, is conditioned at high temperature under vacuum, and weighed after return to the working temperature, giving the mass of clean adsorbent $\mathrm{m}_{\mathrm{a}}$. The adsorbent is then submitted to a flow of a single component, labelled 1, until equilibrium is achieved (weight stabilised, temperature returned to the specified value). This will constitute the initial or background equilibrium state of the experiment and it is also a point of the adsorption isotherm of component 1 . The mass then measured is the sum of the mass of the adsorbent $m_{a}$ and of the adsorbed component $m^{\circ}{ }_{1}$. Here, the subscript 1 designates the adsorbed component, and the superscript o indicates the initial state.

Next, the composition of the incoming gas flow is slightly changed ("perturbed", or incremented) by adding a small flow-rate of component 2 , while keeping constant the total pressure in the measuring cell. This is equivalent to a small change in partial pressure of the components. After returning to equilibrium, the measured mass has undergone a small variation $\delta \mathrm{m}$. From this unique information, and the knowledge of the single component isotherms, we shall show how to extract a value of the activity coefficient of component 2 at infinite dilution in component 1 in the adsorbed phase.

This new equilibrium state, now entirely defined, is then the new initial state, and the procedure can be repeated with a new change in composition, that is of partial pressures, until the full range of the binary composition is covered. We thus obtain a curve of the total adsorbed mass $m_{t}$ versus composition of the gas phase. At the other end of the composition interval, the initial experiment is repeated with components 1 and 2 interchanged, so that the infinite dilution activity coefficient of component 1 in component 2 is obtained. It is recommended to run the whole experiment "backwards", that is with increasing concentration of component 1 , as a cross-check.

The experiment may be carried out in a continuous-flow mode, or in a discontinuous mode, in which the flow through the cell is interrupted while the weight measurement is taken. The latter procedure may also generate slight perturbations, and we found the continuous mode finally more reliable, providing it is operated slow enough (to avoid aerodynamic effects) and sufficient time is allowed for relaxation of the signal after each composition change. We considered the best overall test for attainment of equilibrium is the relative coincidence of the forward and backward curves.

We emphasize that only total weight measurements are done, no further information on the gas phase is required, providing its composition defining each equilibrium state is established with good accuracy. As we shall see now, the use of this approach requires the use of a general thermodynamic model of the adsorbed phase. 


\section{THEORETICAL DEVELOPMENT}

\section{$\underline{\text { Information from the weight measurement }}$}

Let us first formalise the information obtained from the single incremental experiment described above, in the general case where the initial equilibrium state involves the two adsorbed components. This initial state is assumed to be known. Let $\mathrm{m}_{\mathrm{t}}{ }^{\circ}$ be the total mass adsorbed measured, in this initial state, with

$$
m_{t}^{\circ}=m_{1}^{\circ}+m_{2}^{\circ}
$$

Let us introduce the concentrations $q$ in the adsorbed phase, such that

$$
q_{t}=q_{1}+q_{2}=\frac{m_{1}}{m_{a} M_{1}}+\frac{m_{2}}{m_{a} M_{2}}
$$

where $\mathrm{M}_{1}$ and $\mathrm{M}_{2}$ are the molar masses of the adsorbed components [kg.mol ${ }^{-1}$ ], and the adsorbed concentrations $\mathrm{q}_{\mathrm{i}}$ are expressed in [mol kg${ }^{-1}$ adsorbent]. The mole fractions in the adsorbed phase are such that:

$$
\begin{aligned}
& x_{i}=q_{i} / q_{t} \\
& x_{1}+x_{2}=1
\end{aligned}
$$

The composition increment leads to changes in all these variables, and we designate by $\delta \mathrm{z}$ the variation between the new state $\mathrm{z}$ and the initial state $\mathrm{z}^{\circ}$ of any variable $\mathrm{z}$. For small changes the measured mass change $\delta m$ is then :

$$
\delta m_{t}=m-m^{\circ}=\delta m_{1}+\delta m_{2}=m_{a}\left[M_{1} \delta q_{1}+M_{2} \delta q_{2}\right]
$$

together with

$$
\delta q_{i}=\delta\left(x_{i} q_{t}\right)=x_{i}^{\circ} \delta q_{t}+q_{t}{ }^{\circ} \delta x_{i}
$$

and

$$
\delta x_{1}+\delta x_{2}=0
$$

We shall now refer all the changes $\delta z$ to one of them, selected as the partial pressure of component 1, that is, to $\delta p_{1}$. Substituting Eqn. 14 into Eqn. 13 and using Eqns. 5 and 15, we obtain :

$$
\frac{1}{m_{a}} \frac{\delta m_{t}}{\delta p_{1}}=M^{\circ} \frac{\delta q_{t}}{\delta p_{1}}+q_{t}^{\circ}\left(M_{1}-M_{2}\right) \frac{\delta x_{1}}{\delta p_{1}}
$$


Keeping in mind that $\delta \mathrm{m}_{\mathrm{t}}$ is a measured quantity and that the initial state (superscripts 0 ) is known, Eqn. 16 is a first relation between the two unknowns $\delta \mathrm{q}_{\mathrm{t}} / \delta \mathrm{p}_{1}$ and $\delta \mathrm{x}_{1} / \delta \mathrm{p}_{1}$. We now need to establish a second relation between these two unknowns, independent of Eqn. 16. For this purpose, thermodynamic modelling of the adsorbed phase is necessary.

$\underline{\text { Existence of a thermodynamic relation between } \delta \mathrm{q}_{1} / \delta \mathrm{p}_{1}}$ and $\delta \mathrm{x}_{1} / \delta \underline{p}_{1}$

A common binary adsorption equilibrium (without hysteresis) can be represented, at constant temperature and total pressure, as shown on the experimental examples of Figures 5 and 8 which will be presented later.

The adsorbed concentrations $\mathrm{q}_{1}$ and $\mathrm{q}_{2}$ and thus the total concentration $\mathrm{q}_{\mathrm{t}}$, depend only on the partial pressures $p_{1}$ and $p_{2}$ of the two components, and at constant $P$, one only of these partial pressures is independent. One can therefore define ordinary derivatives of these variables with respect to $\mathrm{p}_{1}$. Considering that the change in partial pressure of component 1 is small, the variations can be assimilated to the first derivatives with respect to this partial pressure:

$$
\frac{\delta m}{\delta p_{1}} \rightarrow \frac{d m}{d p_{1}} \quad ; \quad \frac{\delta q_{t}}{\delta p_{1}} \rightarrow \frac{d q_{t}}{d p_{1}} \quad ; \quad \frac{\delta x_{1}}{\delta p_{1}} \rightarrow \frac{d x_{1}}{d p_{1}}
$$

For given adsorbent, $\mathrm{P}, \mathrm{T}$ and species 1 and 2, there is a unique plot such as Figure 5 , where the independent variable has been taken as $p_{1}$. Thus to any value of $p_{1}$ corresponds a unique set of values of $\mathrm{p}_{2}, \mathrm{x}_{1}, \mathrm{x}_{2}, \mathrm{q}_{1}, \mathrm{q}_{2}, \mathrm{q}_{\mathrm{t}}$, as well as their derivatives with respect to $\mathrm{p}_{1}$. Thus $\mathrm{dq}_{t} / \mathrm{dp}_{1}$ and $\mathrm{dx}_{1} / \mathrm{dp}_{1}$ are not independent, and there must exist a relation between these quantities which is determined only by equilibrium, and therefore independent of Eqn. 16. We now proceed to establish algebraically this relation, starting from rather general thermodynamic properties of the adsorbed phase.

\section{THERMODYNAMICS OF THE NON-IDEAL ADSORBED PHASE}

We start with the now classical Adsorbed Solution Theory, introduced initially by [Myers and Prausnitz, 1965]. This approach parallels liquid-vapour equilibrium, with the difference that the surface tension, or spreading pressure $\Pi$, of the adsorbed phase has to be introduced as state variable. The activity coefficients in the adsorbed phase then become a function of the spreading pressure. The constitutive equations of the equilibrium are then (Myers and Prausnitz 1965 ; Kabir et al., 1998 ; Do, 1998), the gas phase being assumed perfect :

$$
\begin{gathered}
p_{i}=P_{i}^{*} x_{i} \gamma_{i} \\
\frac{1}{q_{t}}=\frac{a_{t}}{A}=\frac{\sum \bar{a}_{i} x_{i}}{A}=\sum \frac{a_{i}^{*} x_{i}}{A}+\frac{1}{A}\left(\frac{\partial g^{e x}}{\partial \Pi}\right)_{T, x_{i}}=\sum \frac{x_{i}}{q_{i}^{*}}+\sum x_{i}\left(\frac{\partial \ln \gamma_{i}}{\partial \psi}\right)_{T, x_{i}}
\end{gathered}
$$

In Equation 18, $P_{i} *$ is a fictitious pressure, analogous to the vapour pressure of the pure component in vapour-liquid equilibrium: it is the pressure that species $i$ adsorbed alone would exert, at the same $\mathrm{P}, \mathrm{T}$ and the same spreading pressure $\Pi$ as the mixture. $P_{i}{ }^{*}$ 
is determined from the single component isotherm of $\mathrm{i}$, as a function of $\Pi$. Equation 19 results from the definition of the excess surface $a^{e x}=\Sigma \bar{a}_{i} x_{i}-\Sigma a_{i}^{*} x_{i}$ of the adsorbed phase (two-dimensional analogue of the excess volume) as the derivative of the excess molar Gibbs energy $g^{e x}$ with respect to spreading pressure $\Pi$, and $\psi$ is loading as defined in Equation $2 . \bar{a}_{i}$ is the partial molar surface area of species $\mathrm{i}$, a mixture property. The superscript * refers to single component isotherms and will be explained in more detail below (see for example [Kabir et al, 1998], or the original paper of [Myers and Prausnitz,1965]). $q_{i}{ }^{*}$ is the adsorbed concentration of pure $\mathrm{i}$ corresponding to the partial pressure $p_{i}=P_{i}{ }^{*}$, also obtained from the pure $\mathrm{i}$ isotherm.

In the binary case, the required relation between the derivatives of $\mathrm{q}_{\mathrm{t}}$ and of $\mathrm{x}_{1}$ will be obtained by implicit differentiation of Eqns. 18 and 19, accounting for Eqns. 10, 11 and 12. An essential special case of the present treatment is that of infinite dilution, for which compact, relatively simple, and rather general solutions are found. In the general case, this calculation requires to define a model of the excess Gibbs energy, or of the activity coefficients, not only as a function of the composition of the adsorbed phase $\left(\mathrm{x}_{1}, \mathrm{x}_{2}\right)$, but also as a function of spreading pressure, or of loading $\Psi$. Before doing this in a general fashion, we shall consider some limiting cases, for which the calculations will serve as illustrations, and the result of which will also prove useful in the general cases.

\section{$\underline{\text { Calculation of } \mathrm{dq}_{\mathrm{t}} / \mathrm{dp}_{1}} \underline{\text { in the ideal case (IAS framework) }}$}

When the adsorbed phase is considered ideal, the excess Gibbs energy is zero, and the second term in Eqn 19 disappears. The calculation of the derivative of $\mathrm{q}_{\mathrm{t}}$ then proceeds as follows:

$$
\begin{aligned}
& \frac{d q_{t}}{d p_{1}}=-q_{t}^{2} \frac{d}{d p_{1}}\left(\frac{1}{q_{t}}\right)=-q_{t}^{2} \frac{d}{d p_{1}}\left[\frac{x_{1}}{q_{1}^{*}}+\frac{1-x_{1}}{q_{2}^{*}}\right] \\
& =-q_{t}^{2}\left[\frac{1}{\left(q_{1}^{*}\right)^{2}}\left(q_{1}^{*} \frac{d x_{1}}{d p_{1}}-x_{1} \frac{d q_{1}^{*}}{d p_{1}}\right)+\frac{1}{\left(q_{2}^{*}\right)^{2}}\left(-q_{2}^{*} \frac{d x_{1}}{d p_{1}}-x_{2} \frac{d q_{2}^{*}}{d p_{1}}\right)\right]
\end{aligned}
$$

The derivatives of $\mathrm{q}_{\mathrm{i}}{ }^{*}$ appearing in Eqn. 20 are obtained from the single component isotherms, and can be considered as depending on $\mathrm{P}_{\mathrm{i}}{ }^{*}$ alone. Thus one may write

$$
\begin{gathered}
\frac{d q_{i}^{*}}{d p_{1}}=\frac{d q_{i}^{*}}{d P_{i}^{*}} \frac{d P_{i}^{*}}{d p_{1}} \\
\frac{d P_{i}^{*}}{d p_{1}}=\frac{d}{d p_{1}}\left(\frac{p_{i}}{x_{i}}\right)=\frac{1}{x_{i}} \frac{d p_{i}}{d p_{1}}-\frac{P_{i}^{*}}{x_{i}} \frac{d x_{i}}{d p_{1}}
\end{gathered}
$$


The derivatives of $\mathrm{P}_{\mathrm{i}}{ }^{*}$ are obtained from Eqn. 18 with $\gamma_{\mathrm{i}}=1$. Substituting Eqn. 21 and 22 into Eqn. 20, and after some rearrangements, one obtains:

$$
-\frac{1}{q_{t}^{2}} \frac{d q_{t}}{d p_{1}}=\frac{d x_{1}}{d p_{1}}\left[\frac{1+\xi_{1}^{*}}{q_{1}^{*}}+\frac{1+\xi_{2}^{*}}{q_{2}^{*}}\right]-\frac{\xi_{1}^{*}}{q_{1}^{*} P_{1}^{*}}-\frac{\xi_{2}^{*}}{q_{2}^{*} P_{2}^{*}}
$$

where

$$
\xi_{i}^{*}=\frac{P_{i}^{*}}{q_{i}^{*}} \frac{d q_{i}^{*}}{d P_{i}^{*}}
$$

$\xi_{i}^{*}$ is a parameter depending only on the single component isotherm of which it measures the concavity (the isotherm is concave toward the $\mathrm{p}$ axis for $\xi_{\mathrm{i}}<1$ ). Equation 23 is the sought relation between the derivatives of $\mathrm{q}_{t}$ and of $\mathrm{x}_{1}$.

\section{The infinite dilution limiting case $\left(\mathrm{x}^{\circ} 1 \rightarrow 0\right)$}

This limiting case corresponds to the initial starting point of the experimental procedure. The limit values of the different variables are, when $\mathrm{x}_{1} \rightarrow 0$ :

$\mathrm{x}_{2}{ }_{2} \rightarrow 1 ; \mathrm{p}_{2} \rightarrow \mathrm{P} ; \mathrm{P}^{*}{ }_{2} \rightarrow \mathrm{P} ; \mathrm{q}_{\mathrm{t}} \rightarrow \mathrm{q}_{2 \lim }=\mathrm{q}_{2}{ }_{2}(\mathrm{P}) ; \mathrm{M} \rightarrow \mathrm{M}_{2}$

The fictitious pressure $\mathrm{P} *{ }_{1}$ tends toward a non-zero limit value, which we designate by $\mathrm{P}^{*}{ }_{1,1 \mathrm{im}}$. The corresponding value of $\mathrm{q}^{*}{ }_{1}$ is $\mathrm{q}^{*}{ }_{1, \mathrm{lim}}=\mathrm{q}_{1}\left(\mathrm{P}^{*}{ }_{1, \mathrm{lim}}\right)$. The concavity parameters $\xi_{i}^{*}$ then also tend toward some finite limit value; for example:

$$
\xi_{1 \lim }^{*}\left(x_{1} \rightarrow 0\right)=\frac{P_{1 \lim }^{*}}{q_{1}^{*}\left(P_{1 \lim }^{*}\right)}\left(\frac{d q_{1}}{d p_{1}}\right)_{x_{1}=0}
$$

Equation 23 thus remains valid, with all quantities taking up their limit value. Equation 16 may be rewritten in terms of derivatives with respect to $p_{1}$ instead of variations:

$$
\frac{1}{m_{a}}\left(\frac{d m}{d p_{1}}\right)_{x_{1}=0}=M_{2}\left(\frac{d q_{t}}{d p_{1}}\right)_{x_{1}=0}+q_{2}^{*}(P)\left[M_{1}-M_{2}\right]\left(\frac{d x_{1}}{d p_{1}}\right)_{x_{1}=0}
$$

When Eqns. 23 and 26 are combined to eliminate $\mathrm{dq}_{t} / \mathrm{dp}_{1}$ for example, a relation is obtained between the measured quantity $\mathrm{dm}_{\mathrm{t}} / \mathrm{dp}_{1}$ and the composition change $\mathrm{dx}_{1} / \mathrm{dp}_{1}$ of the adsorbed phase. On the other hand, since we are in the framework of the Ideal Adsorbed Solution Theory, $\mathrm{dx}_{1} / \mathrm{dp}_{1}$ can be calculated analytically [Kabir et al. 1998, Appendix] as:

$$
\left(\frac{d x_{1}}{d p_{1}}\right)_{x_{1}=0}^{I A S}=\frac{1}{P_{1 \lim }^{*}}
$$


Finally, the complete explicit expression for $\mathrm{dm}_{t} / \mathrm{dp}_{1}$, in the IAS framework, is:

$$
\frac{1}{m_{a}}\left(\frac{d m_{t}}{d p_{1}}\right)_{x_{1}=0}^{I A S}=\frac{q_{2}^{*}(P)}{P_{1 \lim }^{*}}\left[M_{1}-M_{2}^{\prime I A S}\right]
$$

where:

$$
M_{2}^{\prime I A S}=M_{2}\left[\frac{q_{2}^{*}(P)}{q_{1 \lim }^{*}}-\xi_{2 \lim }^{*}\left(1-\frac{P_{1 \lim }^{*}}{P}\right)\right]
$$

Practical use and validation

We are now in possession of two values of $\left(\mathrm{dm}_{\mathrm{t}} / \mathrm{dp}_{1}\right)$ at $\mathrm{x}_{1}=0$ : a measured value on one hand, and on the other hand a theoretical value calculated using Eqn.28 and the single component isotherms, in the IAS framework. A similar procedure may then be followed to obtain such values at the other end of the composition interval, that is, for $\mathrm{x}_{2} \rightarrow 0$. One question is how small the increment of composition should be to allow assimilation with the derivative. A way to circumvent this question is to extrapolate the curve obtained with successive increments.

The coincidence of measured and IAS values at each end of the composition interval furnishes a good test of validity of the IAS model. Of course, this validity may be tested more fully by using measurements all along the composition interval. We shall see later on an example how this is handled. But the interest of the IAS approach is not uniquely as a test. When deviations occur between calculated and measured values, they are a measure of non-ideality, and it is of interest to determine whether some "nonideality" coefficients, such as activity coefficients, may be retrieved from these deviations.

This non-ideal approach can only be developed in a somewhat broader thermodynamic framework. The Regular Solution Theory is such a framework. We illustrate this first with the so-called Real Adsorbed Solution (RAS) model.

\section{THE REGULAR-ADSORBED-SOLUTION MODEL}

The Regular Solution Theory relies on two basic assumptions, namely that the excess entropy of mixing $\mathrm{S}^{\mathrm{ex}}$ is zero, and that the volume of mixing $\mathrm{V}^{\mathrm{ex}}$ is zero. But the excess Gibbs energy $\mathrm{G}^{\mathrm{ex}}$ is non-zero, implying that the activity coefficients differ from 1 :

$$
\begin{aligned}
& S^{e x}=-\left(\partial G^{e x} / \partial T\right)_{P, x}=0 \\
& V^{e x}=V^{\text {mix }}=0 \\
& G^{e x}=n R T \sum x_{i} \ln \gamma_{i} \neq 0
\end{aligned}
$$


The condition on entropy Eqn.30, implies that the model used for the excess Gibbs energy is temperature independent, and we shall be referring to this situation in some models used below. Note also that the transposition from solution theory to adsorbed solution theory implies that the derivative in the first equation above be taken at constant spreading pressure $\Pi$ instead of constant pressure P.

In the so-called Real Adsorbed Solution (RAS) model [Costa et al., 1981] the adsorbed phase is non-ideal, in the sense that it obeys Eqn. 18 with $\gamma_{i} \neq 1$. However, the activity coefficients are considered independent of the spreading pressure, and dependent only on composition $\left(\mathrm{x}_{1}, \mathrm{x}_{2}\right)$. This is equivalent to saying that the excess surface is zero, i.e. that the surface area of the adsorbed phase is the sum of the surface areas of the separate components at the same temperature and spreading pressure. The second term in Eqn. 19 therefore cancels. This assumption is analogous to assuming a zero excess mixing volume $\mathrm{V}^{\mathrm{ex}}$ in a three-dimensional phase, i.e. one of the assumption underlying the Regular Solution Theory, Eqn.31. The other assumption $\left(S^{\mathrm{ex}}=0\right)$ will not be used here, and is therefore not necessary. From now on, we shall refer to the RAS model, designating both the Real Adsorbed Solution model and the Regular Adsorbed Solution model.

The implicit differentiation of Eqns. 18 and 19 follows the same lines as in the ideal case, and has been developed in [Kabir et al., 1998]. Thus only the end result is given here :

$$
\begin{gathered}
\frac{d x_{1}}{d p_{1}}=\frac{1}{1+\Delta}\left[\frac{q_{1}}{\gamma_{2} P_{2}^{*} q_{1}^{*}}+\frac{q_{2}}{\gamma_{1} P_{1}^{*} q_{2}^{*}}\right] \\
-\frac{1}{q_{t}^{2}} \frac{d q_{t}}{d p_{1}}=\frac{d x_{1}}{d p_{1}}\left[\frac{1+\xi_{1}^{*}(1+\Delta)}{q_{1}^{*}}-\frac{1+\xi_{2}^{*}(1+\Delta)}{q_{2}^{*}}\right]-\frac{\xi_{1}^{*}}{\gamma_{1} P_{1}^{*} q_{1}^{*}}-\frac{\xi_{2}^{*}}{\gamma_{2} P_{2}^{*} q_{2}^{*}}
\end{gathered}
$$

with

$$
\Delta=x_{1}\left(\frac{\partial \ln \gamma_{1}}{\partial x_{1}}\right)_{T}=x_{2}\left(\frac{\partial \ln \gamma_{2}}{\partial x_{2}}\right)_{T}
$$

The equality of the two terms in Eqn. 35 results from the Gibbs-Duhem constraint.

These equations involve quantities calculable from the single component isotherms (bearing the superscript $*$ ), but also involve the activity coefficients and their dependence on composition. Before introducing the appropriate models for this, let us again consider the starting point of the procedure, the limiting case of infinite dilution.

Limiting case of infinite dilution $\left(\mathrm{x}^{\circ} \underline{1} \rightarrow 0\right)$ 
When $\mathrm{x}_{1} \rightarrow 0$, the quantities involved tend toward the following limits, some of which have already been mentioned in the IAS case:

$$
\begin{aligned}
& x_{1} \rightarrow 0 ; \mathrm{p}_{1} \rightarrow 0 ; \mathrm{q}_{1} \rightarrow 0 ; \mathrm{x}_{2} \rightarrow 1 ; \mathrm{p}_{2} \rightarrow \mathrm{P} ; \mathrm{P}_{2}^{*} \rightarrow \mathrm{P} ; \mathrm{q}_{2} \rightarrow \mathrm{q}_{2}^{*}=\mathrm{q}_{2}^{*}(\mathrm{P}) \\
& \mathrm{P}_{1} \rightarrow \mathrm{P}_{1 \lim }^{*} ; \mathrm{q}_{1}^{*} \rightarrow \mathrm{q}_{1}^{*}\left(\mathrm{P}_{1 \lim }^{*}\right) ; \gamma_{1} \rightarrow \gamma_{1}^{\infty} ; \gamma_{2} \rightarrow 1 ;
\end{aligned}
$$

$\gamma_{1}^{\infty}$ is the so-called infinite dilution activity coefficient. In addition, because $\partial \ln \gamma_{1} / \partial x_{1}$ in principle does not become infinite when $\mathrm{x}_{1} \rightarrow 0$, we have

$$
\operatorname{Lim} \Delta\left(x_{1} \rightarrow 0\right)=0
$$

Because of the Equality in Eqn. 35, this relation implies that:

$$
\frac{\partial \ln \gamma_{2}}{\partial \mathrm{x}_{2}} \rightarrow 0 \quad \text { when } \mathrm{x}_{1} \rightarrow 0
$$

In other words, the Gibbs-Duhem constraint imposes that the pure component activity coefficient approaches the value 1 with zero slope, as the trace component vanishes. With these values, Eqn 33 becomes:

$$
\left(\frac{d x_{1}}{d p_{1}}\right)_{x_{1}=0}^{R A S}=\frac{1}{\gamma_{1}^{\infty} P_{1 \lim }^{*}}
$$

which is to be compared to Eqn. 27. The expression for $\mathrm{dq}_{t} / \mathrm{dp}_{1}$ is Eqn.34 where $\Delta$ is made equal to zero, and the variables take the limiting values indicated above. It is interesting to write the expression for $\mathrm{dm} / \mathrm{dp}_{1}$ in a form similar to Eqn.28:

$$
\frac{1}{m_{a}}\left(\frac{d m_{t}}{d p_{1}}\right)_{x_{1}=0}^{R A S}=\frac{q_{2}^{*}(P)}{\gamma_{1}^{\infty} P_{1 \text { lim }}^{*}}\left[M_{1}-M_{2}^{\prime R A S}\right]
$$

with

$$
M_{2}^{\prime R A S}=M_{2}\left[\frac{q_{2}^{*}(P)}{q_{1 \lim }^{*}}-\xi_{2 \lim }^{*}\left(1-\frac{\gamma_{1}^{\infty} P_{1 \lim }^{*}}{P}\right)\right]
$$

One may observe that the relations for the Real Adsorbed Solution can be derived from the ideal case by simply multiplying $\mathrm{P}^{*}{ }_{1 \lim }$ by $\gamma_{1}{ }^{\infty}$ wherever it occurs.

\section{$\underline{\text { Practical use and validation }}$}

The practical use of these equations aims at determining the infinite dilution coefficients from the experiments at $\mathrm{x}_{1} \rightarrow 0$ and $\mathrm{x}_{2} \rightarrow 0$. This is done simply by rearranging Eqn.38 which is a linear form in $\gamma_{i}^{\infty}$ 


$$
\gamma_{i}^{\infty}=\frac{R}{Q+\left(\frac{d m_{t}}{d p_{1}}\right)_{x_{1}=0}^{\text {measured }}}
$$

with:

$$
\begin{aligned}
& Q=\frac{m_{a}}{P} q_{2}^{*}(P) \xi_{2 \lim }^{*} M_{2} \\
& R=\frac{m_{a}}{P_{1 \lim }^{*}} q_{2}^{*}(P)\left[M_{1}+M_{2}\left(\xi_{2 \lim }^{*}-\frac{q_{2}^{*}(P)}{q_{1 \lim }^{*}}\right)\right]
\end{aligned}
$$

$\mathrm{Q}$ and $\mathrm{R}$ include only information on the pure component isotherms.

There is one special case when $\gamma_{i}{ }^{\infty}$ may be calculated more simply: this is when $\mathrm{q}_{\mathrm{t}}$ is constant, implying in particular that the adsorbed quantity of the single components at the total pressure $\mathrm{P}$ is the same. Then $\mathrm{dm} / \mathrm{dp}_{1}$ is simply related to $\mathrm{dx}_{1} / \mathrm{dp}_{1}$. In Eqns.38 and 39, $\widetilde{M}_{2}^{R A S}$ reduces to $\mathrm{M}_{2}$ and we find a relation somewhat similar to Eqn 35 of [Kabir et al, 1998]. :

$$
\gamma_{i}^{\infty}=\frac{\left(d m / d p_{1}\right)^{I A S}}{\left(d m / d p_{1}\right)^{\text {measured }}}=\frac{m_{a} q_{2}^{*}(P)\left[M_{1}-M_{2}\right]}{P_{1 \lim }^{*}\left(d m / d p_{1}\right)^{\text {measured }}} \quad\left(\text { for } \mathrm{q}_{\mathrm{t}}=\text { constant }\right)
$$

Once the two infinite dilution coefficients $\gamma_{1}^{\infty}$ and $\gamma_{2}^{\infty}$ have been determined, using an experiment at each end of the composition interval, the equilibrium may be completely described using Eqn.18, Eqn. 19 without the spreading pressure term, and a classical two-parameter model for the dependence of activity coefficients on binary composition, such as Wilson, Margules, Van Laar... We shall illustrate this later with an experimental example.

The validation of the RAS model could be done by using measurements of $d m_{t} / d_{1}$ in the full composition range, and comparison with the calculated values, using the full equations 33 and 34 . But instead of using the derivatives, thus the slopes of the equilibrium curves, a simpler and possibly more useful validation may be done by comparing directly the value of the total mass w measured by the balance to a value calculated by:

$$
w=\text { Mass of sample }=m_{a}\left(1+q_{1} M_{1}+q_{2} M_{2}\right)
$$

where $\mathrm{q}_{1}$ and $\mathrm{q}_{2}$ are values calculated using the full model (Eqns.18 and 19 without the second term and the model chosen for activity coefficients).

It should be kept in mind that in such a procedure, one tests the model chosen for the activity coefficients as well as the RAS approach itself. The possible deviations are due 
to the combination of these models, of which the contributions may not be identified separately. Any important deviation between model and measurements may be used to develop a more complete thermodynamic model.

\section{THE SPREADING-PRESSURE-DEPENDENT APPROACH (SPD)}

The RAS model used in the previous section may be very practical, but from a fundamental point of view, it has the drawbacks of neglecting a thermodynamically important feature: the effect of spreading pressure on the non-ideality. A more general model is generated when one considers that the activity coefficients are a function of spreading pressure as well as of composition [Talu and Zwiebel, 1986]. Thus Eqn. 19 has to be considered in its complete form. This model deviates from the Regular Solution Theory, in the sense that the excess mixing area is no longer zero.

The calculation of the derivatives $\mathrm{dq}_{\mathrm{r}} / \mathrm{dp}_{1}$ and $\mathrm{dx}_{1} / \mathrm{dp}_{1}$ has been presented in [Kabir et al., 1998, Appendix] and is not repeated here. The resulting formulae resemble Eqns. 33, 34,35 but contain additional factors:

$$
\begin{aligned}
& \frac{d x_{1}}{d p_{1}}=\frac{1}{1+\Delta}\left[\frac{q_{1}\left(1+\Delta_{1}\right)}{\gamma_{2} P_{2}^{*} q_{1}^{*}}+\frac{q_{2}\left(1+\Delta_{2}\right)}{\gamma_{1} P_{1}^{*} q_{2}^{*}}\right] \\
& -\frac{1}{\mathrm{q}_{\mathrm{t}}^{2}} \frac{d q_{t}}{d p_{1}}=\frac{\mathrm{dx}_{1}}{d p_{1}}\left[\frac{1}{q_{1}^{*}}\left(1+\xi_{1}^{*} \frac{1+\Delta}{1+\Delta_{1}}\right)-\frac{1}{q_{2}^{*}}\left(1+\xi_{2}^{*} \frac{1+\Delta}{1+\Delta_{2}}\right)\right] \\
& -\frac{\xi_{1}^{*}}{q_{1}^{*} \mathrm{P}_{1}^{*} \gamma_{1}\left(1+\Delta_{1}\right)}-+\frac{\xi_{2}^{*}}{q_{2}^{*} \mathrm{P}_{2}^{*} \gamma_{2}\left(1+\Delta_{2}\right)}+\frac{\mathrm{dx}_{1}}{\mathrm{dp}_{1}}\left(\frac{\Delta_{1}}{\mathrm{q}_{1}^{*}}-\frac{\Delta_{2}}{q_{2}^{*}}\right)+\frac{\mathrm{d} \psi}{\mathrm{dp}_{1}}\left(\mathrm{x}_{1} \frac{\partial \Delta_{1}}{\partial \psi}+\mathrm{x}_{2} \frac{\partial \Delta_{2}}{\partial \psi}\right) \\
& \frac{d \psi}{d p_{1}}=(-1)^{i}\left[-\frac{q_{i}^{*}}{P_{i}^{*} x_{i} \gamma_{i}\left(1+\Delta_{i}\right)}+\frac{q_{i}^{*}}{x_{i}} \frac{1+\Delta}{1+\Delta_{i}} \frac{d x_{1}}{d p_{1}}\right] \quad(\mathrm{i}=1 \text { or } 2)
\end{aligned}
$$

with :

$$
\begin{aligned}
& \Delta_{i}=q_{i}^{*}\left(\frac{\partial \ln \gamma_{i}}{\partial \psi}\right)_{T, x} \\
& \Delta=x_{i}\left(\frac{\partial \ln \gamma_{i}}{\partial x_{i}}\right)_{T, \psi}
\end{aligned}
$$

Limiting expressions, corresponding to $\mathrm{x}_{1} \rightarrow 0$, may be obtained using reasonable but general assumptions on the model for activity coefficients. We have noticed already that the Gibbs-Duhem requirement that $\Delta_{\lim }=0$ implies that $\gamma_{2}$ approaches 1 with zero slope in the $(\gamma, x)$ plane. It is reasonable to assume that this property also applies in the $(\gamma, \Psi)$ plane, implying that :

$$
\lim \Delta_{2}\left(x_{1} \rightarrow 0\right)=\lim q_{2}\left(\frac{\partial \ln \gamma^{2}}{\partial^{-1} \psi^{2}-}\right)_{\mathrm{T}, \mathrm{x}}=0
$$


This assumption is coherent with a generalised Gibbs-Duhem constraint, and is satisfied by the example model which we present below. With these properties, the limiting expressions of the derivatives are:

$$
\begin{aligned}
& \left(\frac{d x_{1}}{d p_{1}}\right)_{x_{1}=0}^{S P D}=\left(\frac{d x_{1}}{d p_{1}}\right)_{x_{1}=0}^{R A S} \quad \text { (see Equation 37) } \\
& \frac{1}{m_{a}}\left(\frac{d m_{t}}{d p_{1}}\right)_{x_{1}=0}^{S P D}=\frac{q_{2}^{*}}{\gamma_{1}^{\infty} P_{1 \lim }^{*}}\left[M_{1}-M_{2}^{\prime S P D}\right]
\end{aligned}
$$

Equation 50 has the same form as Eqn.38, but with:

$$
M_{2}^{\prime S P D}=M_{2}\left[\frac{q_{2}^{*}(P)}{q_{1 \lim }^{*}}\left(1+\Delta_{1 \lim }\right)-\left[\xi_{2 \lim }^{*}-\left(q_{2}^{*}(P)\right)^{2} \Delta_{2^{2}}^{\prime}\right]\left[1-\gamma_{1}^{\infty} \frac{P_{1 \lim }^{*}}{P}\right]\right]
$$

and

$$
\Delta_{2}^{\prime}=\left(\frac{\partial^{2} \ln \gamma_{2}}{\partial \psi^{2}}\right)_{T, x_{1}=0}=\left(\frac{\partial \Delta_{2}}{\partial \psi}\right)_{T, x_{1}=0}
$$

Equation 51 is to be compared to Equation 39. A further simplification, to be found in the example model below, is obtained when $\Delta^{\prime}{ }_{2}=0$. In what follows, we illustrate the calculation with what is probably the simplest such model proposed in the literature.

\section{The Iso-Active Sorbent model of Kopatsis and Myers (ISAC)}

Kopatsis [1988] and [Siperstein et al., 1999] in the framework of the so-called IsoActive-Solvent Theory (ISAC) indicate a method of construction of the excess free energy function by combining a classical, composition dependent model (Margules, Van Laar, Wilson...) with an experimental function of loading $\psi$. Let us illustrate the calculation for a one-parameter Margules equation. The above authors propose, for the molar excess Gibbs energy:

$$
g^{e x}=B x_{1} x_{2}\left(1-e^{-C \psi}\right)
$$

from which the activity coefficients are calculated by:

$$
R T \ln \gamma_{i}=\left(\frac{\partial g^{e x}}{\partial n_{i}}\right)_{T, \psi, \psi,}=B x_{j}^{2}\left(1-e^{-C \psi}\right)
$$


The expressions for $\Delta$ and $\Delta_{\mathrm{i}}$, from Eqns. 46 and 47 and their derivatives appearing in Eqn. 44 are calculated as:

$$
\begin{aligned}
& \Delta_{i}=\frac{q_{i}^{*} B C}{R T} x_{j}^{2} e^{-C \psi} \\
& \left(\frac{\partial \Delta_{i}}{\partial \psi}\right)_{T, x}=-\frac{q_{i}^{*} B C^{2}}{R T} x_{j}^{2} e^{-C \psi} \\
& \Delta=-\frac{2 B x_{1} x_{2}}{R T}\left(1-e^{-C \psi}\right)
\end{aligned}
$$

The limit values at infinite dilution of component 1 say, are readily obtained from these expressions. Notice that the property assumed above in the SPD approach, Eqn.48, is satisfied. In addition $\Delta^{\prime}{ }_{2}\left(\mathrm{x}_{1}=0\right)=0$, implying that the coefficient of $\mathrm{d} \psi / \mathrm{dp} \mathrm{p}_{1}$ in Eqn.44 vanishes, and that Eqn.51 applies in its simplified form.

With these properties, the expressions for the derivatives $\mathrm{dx}_{1} / \mathrm{dp}_{1}$ and $\mathrm{dm}_{\mathrm{t}} / \mathrm{dp}_{1}$ are identical to Eqns 37 and 38, but with Eqn.39 replaced by Eqn. 51 with $\Delta_{2}^{\prime}=0$. Notice that the only change is the appearance of the term

$$
\Delta_{1 \lim }=\frac{q_{1 \lim }^{*} B C}{R T} e^{-C \psi_{1 \lim }}
$$

This cancels for spreading pressure independent activity coefficients. In Eqn.58, the value $\psi_{1, \text { lim }}$ is calculated from the definition relation of loading $\psi$, in the framework of the adsorbed solution theory, from the single component isotherm:

$$
\psi_{1 \lim }=\psi\left(\mathrm{x}_{1}=0\right)=\int_{0}^{\mathrm{P}_{1 \lim }^{*}} \frac{\mathrm{q}_{1}^{*}}{\mathrm{P}} \mathrm{dp}
$$

\section{Practical use, validation and extension}

The practical use of these new relations is not basically different from the RAS case. The expression of $\mathrm{dm}_{t} / \mathrm{dp}_{1}$ (Eqn.50) can be solved for $\gamma_{1}{ }^{\infty}$ which is the only variable that is not calculable a priori from the single component isotherms of both components. Clearly, the same procedure is applied at the other end of the composition interval for $\mathrm{x}_{2} \rightarrow 0$, to obtain $\gamma_{2}{ }^{\propto}$. Once the $\gamma^{\propto}$ are obtained, Eqn.54 is written twice for the limiting values:

$$
\begin{aligned}
& R T \ln \gamma_{1}^{\infty}=B\left(1-e^{-C \psi_{1 \lim }}\right) \\
& R T \ln \gamma_{2}^{\infty}=B\left(1-e^{-C \psi_{2 \lim }}\right)
\end{aligned}
$$


and this system is solved for B and C. The full description of the thermodynamic coadsorption equilibrium is therefore achieved.

Again, the most straightforward method of testing and possibly validating this model is to recalculate the complete binary curves, using Eqns.18 and 19 and the fitted relations for the $\gamma_{i}$, and to compare the weighed mass to the mass calculated using Eqn.42 for the full composition range.

\section{AN EXPERIMENTAL EXAMPLE}

This example concerns the co-adsorption of $\mathrm{CO} 2$ and $\mathrm{CH} 4$ on Norit activated carbon in the context of modelling Hydrogen purification by PSA. The total pressure is near one atmosphere and the temperature near ambient. The corrected weight of the degassed adsorbent sample is $m_{a}=0.96927 \mathrm{~g}$.

\section{The first step is to measure and exploit the single component adsorption isotherms.}

This was done up to 5 bars using the micro-balance in a conventional way. For measurements below one bar, the measuring cell was equilibrated with a flow of mixture of the adsorbed component with helium (the adsorption of which is negligible under these conditions), with varying partial pressure of the adsorbed component. For pressures higher than 1 bar, the cell can be equilibrated with varying total pressures of the pure adsorbed component. Measurements at partial pressures somewhat higher than what is used in the binary experiments are required for the calculation of the fictitious pressures $\mathrm{P}^{*}$ appearing in Eq.18 and subsequently. The measured isotherms are plotted in Figure 2, and can be represented with a good fit by a Langmuir-type isotherm with the data and parameters given in Table 1.

$$
q_{i}=\frac{q_{i m} k_{i} p_{i}}{1+k_{i} p_{i}}
$$

Table 1:

Parameters of the Langmuir representation for $\mathrm{CO} 2$ and $\mathrm{CH} 4$ isotherms on Norit AC.at $\mathrm{T}=295^{\circ} \mathrm{K}$ and $\mathrm{P}=1.011 \mathrm{bar}$

\begin{tabular}{|c|c|c|c|}
\hline \multicolumn{2}{|c|}{$\begin{array}{l}\text { Component } \\
\text { Temperature }\end{array}$} & $1=\mathrm{CO} 2$ & $2=\mathrm{CH} 4$ \\
\hline \multirow{2}{*}{$295^{\circ} \mathrm{K}$} & $\underset{\left(m o l . \mathrm{kg}^{-1}\right)}{\mathrm{q}_{\mathrm{m}}}$ & 7.94 & 4.87 \\
\hline & $\begin{array}{c}\mathrm{k} \\
\left(\mathrm{bar}^{-1}\right) \\
\end{array}$ & 0.496 & 0.389 \\
\hline \multirow{2}{*}{$314^{\circ} \mathrm{K}$} & $\begin{array}{c}\mathrm{q}_{\mathrm{m}} \\
\left(\mathrm{mol}_{\mathrm{kg}}^{-1}\right)\end{array}$ & 6.48 & 4.59 \\
\hline & $\begin{array}{c}\mathrm{k} \\
\left(\mathrm{bar}^{-1}\right)\end{array}$ & 0.358 & 0.182 \\
\hline
\end{tabular}

As shown in Appendix, the Langmuir isotherm yields analytical expressions for most of the quantities involved in the thermodynamic calculations. From these isotherms, 
the spreading pressure $\Pi$ or more conveniently, the loading $\psi$ for each component can be constructed by integration using equation A3 in Appendix. The loading curves are shown on Figure 3. On this figure are also indicated the graphical meaning of the limit values of $\mathrm{P}^{*}\left(\mathrm{P}^{*}{ }_{1 \lim }\right.$ and $\left.\mathrm{P}^{*}{ }_{2 \lim }\right)$ and of $\Psi\left(\Psi_{1 \lim }\right.$ and $\left.\Psi_{2 \lim }\right)$.

The numerical values of these quantities are obtained from equations A6 and A9. The limiting values of the adsorbed quantities $\mathrm{q}^{*}$ corresponding to the fictitious pressures $\mathrm{P}^{*}{ }_{\lim }$ and to the total pressure $\mathrm{P}$ are calculated from the isotherms or Eq. A7, and finally the limit values of the curvature parameters $\xi$ are calculated from equations 16 or A8. All the corresponding values are gathered in Table 2. Notice that so far, we have only used information from the pure component isotherms, and none from co-adsorption experiments.

In the present work, we have used the analytical approach described above, based on Langmuir isotherms. However, the binary predictions may be quite sensitive to the "quality" of the single component isotherms, and if one has very good experimental data, it may be better to use a purely numerical approach, possibly fitting the data with nonphysical interpolation functions, such as splines.

Table 2

Characteristic parameters of adsorption of $\mathrm{CO} 2$ and $\mathrm{CH} 4$ at $\mathrm{T}=295^{\circ} \mathrm{K}$ and $\mathrm{P}=1.011 \mathrm{bar}$

\begin{tabular}{|c|c|c|c|}
\hline \multicolumn{2}{|c|}{ Component $\rightarrow$} & $1=\mathrm{CO} 2$ & $2=\mathrm{CH} 4 \quad\left(\mathrm{x}_{2} \rightarrow 0\right)$ \\
\hline$\psi_{i \lim }$ & mol. $\mathrm{kg}^{-1}$ & $\psi_{1 \lim }=$ & $\psi_{2 \lim }=$ \\
\hline $\mathbf{P} * \lim$ & bar & $\mathrm{P} *_{1 \lim }=0.458$ & $\mathrm{P}^{*}{ }_{2 \lim }=2.397$ \\
\hline $\mathbf{q *}\left(\mathbf{P}_{\lim }\right)$ & mol.kg ${ }^{-1}$ & $\mathrm{q}^{*}{ }_{1}\left(\mathrm{P}_{1 \mathrm{lim}}\right)=1.352$ & $\mathrm{q}^{*}{ }_{2}\left(\mathrm{P}_{2 \lim }\right)=2.213$ \\
\hline $\mathbf{q}^{*}(\mathbf{P})$ & mol. $\mathrm{kg}^{-1}$ & $\mathrm{q}^{*}(\mathrm{P})=2.491$ & $\mathrm{q}_{2}(\mathrm{P})=1.270$ \\
\hline$\xi$ & - & $\xi_{1 \lim }=$ & $\xi_{2 \lim }=$ \\
\hline
\end{tabular}

\section{The next step is to run the perturbation experiments and look at the limits.}

The procedure was described at the beginning of this paper. The overall result is shown on Figure 4 for two temperatures, 295 and $314^{\circ} \mathrm{K}$. The total adsorbed mass $\mathrm{m}_{\mathrm{t}}$, divided by the mass $m_{a}$ of the "clean" adsorbent, is plotted as measured versus partial pressure of $\mathrm{CO} 2$ (component 1). An interesting experimental verification is done in building the curve "from both ends", that is in our example, starting with pure $\mathrm{CH} 4$ and increasing progressively the $\mathrm{CO} 2$ partial pressure, and after reaching $100 \% \mathrm{CO} 2$, perform the reverse operation. The "upwards" and "downwards" points are distinguished on the figure, and a good consistency is observed. The total pressure in these experiments undergoes slight changes, of the order of $0.5 \%$ between the upwards and the downwards experiments. The continuous curves are a third-order polynomial fit of the overall data.

At the extremities of these curves, (limit of a small partial pressure change upon a pure component) one obtains an experimental value of $\mathrm{dm}_{\mathrm{t}} / \mathrm{dp}$. This value is then compared to the value calculated using the IAS equations 28 and 29, with the parameters of Table 2 . This comparison is shown in Table 3 for $295^{\circ} \mathrm{K}$. 
Table 3

Experimental and IAS values of $\mathrm{dm}_{\mathrm{t}} / \mathrm{dp}$ at the composition limits $\left(295^{\circ} \mathrm{K}\right)$

\begin{tabular}{|c|c|c|}
\hline Values of $\left(\mathrm{dm}_{\mathrm{t}} / \mathrm{dp}_{\mathrm{i}}\right) \quad\left(\right.$ g.bar $\left.^{-1}\right)$ & $\left(d m / d p_{i}\right)$ measured & $\left(\mathrm{dm} / \mathrm{dp} p_{\mathrm{i}}\right)^{\mathrm{IAS}}$ calc (Eq.28) \\
\hline $\mathrm{x}_{1}=\mathrm{x}_{\mathrm{CO} 2} \rightarrow 0$ & $\left(\mathrm{dm} / \mathrm{dp}_{1}\right)=0.14846$ & $\left(\mathrm{dm} / \mathrm{dp}_{1}\right)=0.12109$ \\
\hline $\mathrm{x}_{2}=\mathrm{x}_{\mathrm{CH} 4} \rightarrow 0$ & $\left(\mathrm{dm} / \mathrm{dp}_{2}\right)=-0.08210$ & $\left(\mathrm{dm} / \mathrm{dp}_{2}\right)=-0.10641$ \\
\hline
\end{tabular}

It can be observed that the measured and calculated values are in the "good" order of magnitude and sign, but we can certainly expect a better fit with a more elaborate model.

\section{Next, the full equilibrium is calculated using the IAS algorithm}

A convenient algorithm for the IAS calculations is the following:

- pick a series of values of $\Psi$ between $\Psi_{1 \lim }$ and $\Psi_{2 \lim }$ of Table 2

- for each $\Psi$ compute $\mathrm{P}^{*}$ from Eq.A3 or A4

- obtain the solid phase composition $\mathrm{x}_{\mathrm{i}}$ from:

$$
\mathrm{x}_{1}=\left(\mathrm{P} *_{2}-\mathrm{P}\right) /\left(\mathrm{P} *_{2}-\mathrm{P} *_{1}\right) \quad \mathrm{x}_{2}=1-\mathrm{x}_{1}
$$

- obtain $\mathrm{q}^{*}\left(\mathrm{P}_{1}{ }_{1}\right)$ and $\mathrm{q}_{2}\left(\mathrm{P}_{2}\right)$ from the isotherms

- compute the total adsorbed quantity $\mathrm{q}_{\mathrm{t}}$ from Eq. 19 without the second term

- obtain the individual adsorbed quantities $\mathrm{q}_{\mathrm{i}}$ as $\mathrm{q}_{\mathrm{t}} \cdot \mathrm{x}_{\mathrm{i}}$

- obtain the gas phase composition $\mathrm{y}_{\mathrm{i}}$ from Eq. 18 as $\mathrm{x}_{\mathrm{i}} . \mathrm{P}_{\mathrm{i}}^{*} / \mathrm{P}$

Figure 5 shows the plot of these calculated binary isotherms, where the adsorbed quantities are expressed in mass and referred to a unit mass of adsorbent. The IASpredicted curve of the total adsorbed mass can now be compared to the experimental result. A significant difference is observed which may justify to resort to a more elaborate model.

\section{The limiting activity coefficients are then determined}

The measured values of $\mathrm{dm}_{t} / \mathrm{dp}$ (Table 3 ) can be used to evaluate limiting activity coefficients, using Eq.40. The results are in Table 4 and we observe that the values of $\gamma^{\infty}$ are smaller than 1.

Table 4

Calculation of infinite dilution activity coefficients in adsorbed phase from the measured limit values of $\mathrm{dm}_{\mathrm{t}} / \mathrm{dp}\left(295^{\circ} \mathrm{K}\right)$

\begin{tabular}{|c|c|c|}
\hline $\begin{array}{c}\text { Infinite dilution } \\
\text { activity coefficients }\end{array}$ & $\begin{array}{c}\mathbf{C O 2} \\
\mathbf{x}_{\mathbf{1}}=\mathbf{x}_{\mathrm{CO} 2} \rightarrow \mathbf{0}\end{array}$ & $\begin{array}{c}\mathbf{C H 4} \\
\mathbf{x}_{\mathbf{2}}=\mathbf{x}_{\mathbf{C H} 4} \rightarrow \mathbf{0}\end{array}$ \\
\hline Coefficient Q (Eq.41) & 0.0359 & 0.1256 \\
\hline Coefficient R (Eq.41) & 0.1970 & 0.0192 \\
\hline$\gamma \propto$ (Eq.40) & $\gamma_{1} \propto=0.8515$ & $\gamma_{2} \propto=0.4417$ \\
\hline
\end{tabular}




\begin{tabular}{|l|l|l|}
\hline Ln $\gamma \propto$ & -0.16075 & -0.81712 \\
\hline
\end{tabular}

\section{Models for non-ideal solutions are tested}

We can now implement some classical model for activity coefficients. Five models involving two adjustable parameters have been tested here: Wilson, Van Laar, Margules, Flory-Huggins, and ISAC. The first four are presented and can be found in most chemical thermodynamics books, for example [Sandler, 1999]. For ISAC, one has to refer to the original publication by [Kopatsis et al., 1988]. They all derive from a form of the Gibbs excess energy and satisfy the Gibbs-Duhem constraint. The Van Laar model corresponds to the Regular Solution assumptions, including a zero excess entropy of mixing. The Wilson, Margules and Flory-Huggins models are used with the RAS assumption of zero excess surface of mixing, i.e. without the last term in Eqn.19.

The ISAC model contains an explicit dependence of Gibbs energy and of activity coefficients on loading (SPD framework), and therefore accounts for this term in Eqn.19. Table 5 gathers the constitutive equations of these five models. Using the values of $\gamma^{\infty}$ thus determined and the limiting equations for $\operatorname{Ln} \gamma^{\infty}$, the unknown parameters are determined directly for the Van Laar and the Margules equations. For the Wilson, ISAC and FloryHuggins models, the couple of non-linear equations can be reduced to a single equation which needs to be solved by a numerical search, but which has seemingly a unique physical solution. The values of the parameters of the five models are given in Table 6 , and Figures $6 \mathrm{a}$ and $6 \mathrm{~b}$ are a representation of the variation of the activity coefficients with composition. It is seen that the variation of the $\gamma$ is qualitatively similar except for the Wilson model, and this will have a significant influence on the isotherms themselves. Notice that Ln $\gamma$ is essentially negative $(\gamma<1)$ for all models and over the whole range (negative deviation from Raoult's law) except a very slightly positive zone for $\mathrm{CH} 4$ with Margules, and a practically zero zone for $\mathrm{CO} 2$ with Flory-Huggins. Of course, all models satisfy the conditions that when the mole fraction of a component tends to 1 , the logarithm of its activity coefficient tends to 0 with zero slope, as required by the Gibbs-Duhem constraint.

The Flory-Huggins model has a particular status here, since it is not a regular solution model (the excess entropy is non-zero). It is actually the only model that does not satisfy Herington's consistency test [Herington, 1947]:

$$
\int_{0}^{1} \ln \left(\frac{\gamma_{1}}{\gamma_{2}}\right) d x=0 \quad(\text { const } T \text { and } \Psi)
$$

We believe that this is due to an improper use of this model (imposing the assumption of zero excess area) and not to an intrinsic inconsistency. In addition, the value of the parameter $\mathrm{m}$, given in Table 6 , has visibly no relation with the ratio of molar volumes of the two components, as the physical interpretation of this model implies. On the other hand, it could be interpreted more realistically as space, or number of sites, occupied by the adsorbed molecules on the adsorbent surface. The reason for testing this model is its 
relation to the sorption in polymers, and thus possibly to adsorption, but its use here should be considered as purely empirical.

Table 6

Numerical values of model parameters for activity coefficients

$\mathrm{CO} 2+\mathrm{CH} 4$ on Norit $\mathrm{AC}$ at $295^{\circ} \mathrm{K}$

\begin{tabular}{|l|l|l|l|l|}
\hline Wilson & Van Laar & Flory-Huggins & Margules & ISAC \\
\hline & & & $\alpha_{1}=-1.4733$ & \\
$\Lambda_{12}=0.00708$ & $\alpha=-0.1608$ & $\mathrm{~m}=3.396$ & $\beta_{1}=1.3125$ & $\mathrm{~B} / \mathrm{RT}=0.05310$ \\
$\Lambda_{21}=6.11111$ & $\beta=-0.8170$ & $\chi=0.3563$ & $\alpha_{2}=0.4955$ & \\
& & & $\beta_{2}=-1.3125$ & $\mathrm{C}=-0.95951$ \\
\hline
\end{tabular}

\section{The full equilibrium is now computed with these different models.}

This implies solving the RAS equations, that is Equation 18 with the activity coefficients, and Equation 19 (without the spreading pressure dependent term for the first four models, with this term for the ISAC model). The algorithm is not basically different from that presented above in Section 3, except that the calculation of the adsorbed phase composition is not explicit, and requires a simple numerical search.

A first interesting and useful test is to compare the total adsorbed mass curves for the different models with the experimental results. This is done on Figures $7 \mathrm{a}$ and $7 \mathrm{~b}$ for two temperatures, $295^{\circ} \mathrm{K}$ and $314^{\circ} \mathrm{K}$. The data and parameters for this second temperature are gathered below in Table 9 and will be discussed later. It is seen that at $295^{\circ} \mathrm{K}$, all models give visually "correct" results, with an underestimation for IAS, a better fit for Margules and a relatively poorer one for Wilson in the low $\mathrm{CO} 2$ region. The picture is quite different at $314^{\circ} \mathrm{K}$, where none of the models gives really excellent results. Margules is again the best choice. Table 7 gives quantitative measures of the standard deviation and the arithmetic average deviation of the models with experiment, and confirms the visual impression.

Figure $7 \mathrm{c}$ illustrates a peculiarity of the present method which we want to emphasize. It is a plot of the same results as Figure $7 \mathrm{a}$, at $295^{\circ} \mathrm{K}$, but using the more usual mole concentration in the adsorbed phase, instead of the mass concentration. The problem of this representation is that it is not a direct representation of the experimental result, since the adsorbed phase composition has to be calculated using one of the models (in the case of Figure $7 \mathrm{c}$, with used the Margules relation). Therefore, the validation and comparison with experiment should be done exclusively with plots such as Figures $7 \mathrm{a}$ and $\mathrm{b}$.

Table 7

Deviation of models from experiment for the total adsorbed mass $\left(295^{\circ} \mathrm{K}\right)$

\begin{tabular}{|c|c|c|c|c|c|c|}
\hline $\begin{array}{c}\text { Model } \rightarrow \\
\text { Deviation\% }\end{array}$ & IAS & Wilson & Van Laar & Flory-H. & Margules & ISAC \\
\hline Standard deviation & 13.21 & 9.17 & 1.82 & 3.40 & 0.79 & 2.19 \\
\hline Mean deviation & 11.52 & 7.87 & 1.52 & 2.93 & 0.63 & 1.85 \\
\hline
\end{tabular}


Figures $8 \mathrm{a}$ and $8 \mathrm{~b}$ show the reconstitution of the individual adsorption curves for the two components, at the two temperatures, using the Margules model. Obviously, similar diagrams are easily generated with the other models, but the only evaluation criterion that we have is the total adsorbed mass, as shown above. It may be tempting to conclude that the Margules model is the best choice in general, owing to its simplicity and to the good present results. There are no theoretical grounds for such a general conclusion though.

A further representation of the full equilibrium is the "phase diagram", where the adsorbed phase composition $\mathrm{x}$ is plotted versus the gas phase composition $\mathrm{y}$ in equilibrium. Figure 9 shows this diagram as constructed with the different models at $295^{\circ} \mathrm{K}$, and indicates that this representation has little sensitivity to the choice of the model. The differences are emphasised and the relative position of the curves appears more clearly when one plots as ordinate the difference $x-y$, in other words, the vertical distance of the curve from the diagonal, as in Figures 10.

\section{DISCUSSION AND EXTENSIONS}

\section{Validation with independent data.}

It is of interest to test the complete approach using "complete" data, that is where the adsorbed quantities of each component is measured, not just the total adsorbed mass. For this purpose, we have used co-adsorption data furnished by L'Air Liquide for a total pressure of 2.06 bars and $293^{\circ} \mathrm{K}$. The adsorbed concentrations were determined using a material balance on a batch equilibration technique with measurement of the gas phase composition at equilibrium, and the total adsorbed quantity curve is obtained by their summation. These experimental data appear as discrete points on Figure 11. The curve of total adsorbed mass is then smoothed with a polynomial to evaluate the limiting slopes $\mathrm{dm} / \mathrm{dp}$. We then recalculated the characteristic parameters at this new total pressure from the single component isotherms of Figure 2, neglecting the temperature difference between 293 and $295^{\circ} \mathrm{K}$, and the infinite dilution activity coefficients are determined as in the experimental example above, using only the limiting slopes of the smoothed total adsorbed mass curve. Table 8 summarizes the numerical results.

Table 8: Data and parameters for the $\mathrm{CO} 2-\mathrm{CH} 4$ isotherm at $293^{\circ} \mathrm{K}, \mathrm{P}=2.06$ bar

\begin{tabular}{|l|l|l|l|}
\hline $\mathrm{i}$ & $1=\mathrm{CO} 2$ & $2=\mathrm{CH} 4$ & units \\
\hline$\psi_{\lim }$ & 2.598 & 5.122 & $\mathrm{~mol} . \mathrm{kg}^{-1}$ \\
\hline $\mathrm{P}_{\lim }$ & 0.884 & 5.578 & bar \\
\hline $\mathrm{q}_{\lim }(\mathrm{P})$ & 3.862 & 2.031 & $\mathrm{~mol} . \mathrm{kg}^{-1}$ \\
\hline $\mathrm{q}_{\lim }\left(\mathrm{P}_{\lim }\right)$ & 2.263 & 3.205 & $\mathrm{~mol} . \mathrm{kg}^{-}$ \\
\hline$\xi_{\lim }$ & 1.377 & 1.092 & - \\
\hline$\left(\mathrm{dm} / \mathrm{dp}_{\mathrm{i}}\right)_{\mathrm{xi}=0}$ & 0.1058 & -0.0490 & $\mathrm{~g} \cdot \mathrm{bar}^{-1}$ \\
\hline $\mathrm{Q}_{\mathrm{i}}$ & 0.0167 & 0.1069 & $\mathrm{~g} \cdot \mathrm{bar}^{-1}$ \\
\hline $\mathrm{R}_{\mathrm{i}}$ & 0.1049 & 0.0158 & $\mathrm{~g} \cdot \mathrm{bar}^{-1}$ \\
\hline$\gamma_{\mathrm{i}}$ & 0.856 & 0.273 & - \\
\hline
\end{tabular}


These activity coefficients were then used with the Margules model to construct the binary co-adsorption isotherms shown as continuous lines on Figure 11. The standard deviation on the total adsorbed mass is about $3 \%$, while it is of the order of $7 \%$ for $\mathrm{CO} 2$ and $15 \%$ for $\mathrm{CH} 4$. The procedure over-predicts $\mathrm{CH} 4$ adsorption and under-predicts $\mathrm{CO} 2$ adsorption. It is noteworthy that the value of $\gamma_{1}^{\infty}$ is almost the same as at 1 bar, and that the results are rather sensitive to this value, while they are relatively insensitive to the value of $\gamma_{2}^{\infty}$, which is very different from that at 1 bar..

\section{Model dependence and number of parameters.}

The approach presented here starts with the determination of $\gamma_{1}^{\infty}$ and $\gamma_{2}^{\infty}$. The values found are "mathematically univocal", meaning that there is only one set of values satisfying the equations that determine them, given the measured quantities. Within the RAS approach, the values found are also model-independent, i.e. they are the same for Wilson, Van Laar, Margules or any other spreading pressure independent model for composition dependence. In addition, the two parameters of the models used here are also uniquely determined. They account for the full composition dependence of the activity coefficients.

In the SPD approach on the other hand, the values of $\gamma_{1}^{\infty}$ and $\gamma_{2}^{\infty}$ depend on the spreading pressure dependence postulated, for instance, that of ISAC, and in that sense are model-dependent. This dependence requires the introduction of at least one parameter, so that only one parameter is left to account for the composition dependence. The question posed is then how to handle models with more parameters, for example combining a twoparameter Margules or Wilson expression for the composition dependence with the exponential factor of the ISAC model. This was done for example in the paper by [Myers, 1989], by an optimization method of the three parameters, using binary data at different pressures. A similar approach could in principle be taken here using all the experimental data available at one pressure, not just the limiting $\gamma$ 's. As an initial guess, one may use the infinite dilution $\gamma$ values estimated as for RAS. But the "one pressure" fitting approach does not discriminate between the effect of the spreading pressure and the effect of composition on the activity coefficients, and is therefore a relatively blind fitting that does not guarantee coherence. We discuss this question further in connection with the pressure dependence of activity coefficients.

\section{Pressure dependence of activity coefficients and prediction at other pressures.}

As suggested by [Van der Vaart et al., 2000], it would seem a priori reasonable to assume that the activity coefficients are independent of total pressure, an assumption coherent with the picture of the Regular Adsorbed Solution Theory. To substantiate this assumption, one may notice that the Helmholtz energy of condensed phases is practically pressure independent and if the excess surface of mixing is assumed zero, the Gibbs excess energy is equal to the Helmholtz excess energy. This does not strictly imply independence with respect to spreading pressure, but probably a weak dependence. A possible application of this approach would then be to predict the co-adsorption of the same constituents under different pressures. We have thus tried to represent the binary system at 2.06 bar using the activity coefficients at 1 bar. The resulting curves give a representation (not shown here) that is only slightly poorer than that of Figure 11, with the same trends (good fit for the total mass, over-prediction of $\mathrm{CH} 4$ adsorption and under-prediction of 
$\mathrm{CO} 2$ adsorption). The pressure independence of the activity coefficients may thus be taken as an approximation.

Let us now compare the values obtained above at 1.01 bar (Table 4) and at 2.06 bar (Table 8). It is seen that $\gamma \propto\left(\mathrm{x}_{\mathrm{CO} 2}=0\right)$ practically has the same value, and can thus be considered pressure independent. Such is not the case for $\gamma \propto\left(\mathrm{x}_{\mathrm{CH} 4}=0\right)$, which is almost divided by two when doubling the pressure. This trend has a low sensitivity to the value of $\mathrm{dm} / \mathrm{dp}$, and is mostly sensitive to the properties of the single component isotherms. It is clear that for accurate values of the infinite dilution activity coefficient, pressure independence is not acceptable, even though, as mentioned above, the binary curves are relatively insensitive to $\gamma_{2}{ }^{\infty}$.

For a more accurate prediction of the binary curves, changing the limiting activity coefficient with pressure is apparently not sufficient. What is actually missing here is a detailed description of the spreading pressure dependence. In a forthcoming publication, we shall show how a complete 4-parameter SPD model can be built univocally, using data at two pressures, without recourse to a fitting method. The methodology and the calculations are too long to be presented in the present paper.

\section{Temperature dependence of activity coefficients.}

As for temperature, there is no reason to expect any simple dependence, and clearly new single component isotherms have to be measured as well as new activity coefficients. We have made measurements of the total adsorbed mass at $314^{\circ} \mathrm{K}$ and 1.01 bar (Figure 4) and determined the corresponding activity coefficients. Table 9 gives the corresponding parameters and activity coefficients, Figure $7 \mathrm{~b}$ shows the representation of the total adsorbed mass, and Figure $8 \mathrm{~b}$ shows the binary isotherms.

Table 9.

Data and parameters for the $\mathrm{CO} 2-\mathrm{CH} 4$ isotherm at $314^{\circ} \mathrm{K}, \mathrm{P}=1.01$ bar

\begin{tabular}{|l|l|l|l|}
\hline $\mathrm{i}$ & $1=\mathrm{CO} 2$ & $2=\mathrm{CH} 4$ & units \\
\hline $\mathrm{q}_{\mathrm{m}}{ }^{*}$ & 6.48 & 4.59 & $\mathrm{~mol}^{-1} \mathrm{~kg}^{-1}$ \\
\hline $\mathrm{b}_{\mathrm{i}}$ & 0.358 & 0.182 & $\mathrm{bar}^{-1}$ \\
\hline$\psi_{\lim }$ & 0.737 & 1.967 & $\mathrm{~mol} \cdot \mathrm{kg}^{-1}$ \\
\hline $\mathrm{P}_{\lim }$ & 0.347 & 3.123 & $\mathrm{bar}$ \\
\hline $\mathrm{q}_{\lim }(\mathrm{P})$ & 1.718 & 0.690 & $\mathrm{~mol} \cdot \mathrm{kg}^{-1}$ \\
\hline $\mathrm{q}_{\lim }\left(\mathrm{P}_{\lim }\right)$ & 0.706 & 1.624 & $\mathrm{~mol} \cdot \mathrm{kg}^{-}$ \\
\hline$\xi_{\lim }$ & 1.141 & 1.539 & - \\
\hline$\left(\mathrm{dm} / \mathrm{dp}_{\mathrm{i}}\right)_{\mathrm{xi}=0}$ & 0.0929 & -0.0312 & $\mathrm{~g} \cdot \mathrm{bar}^{-1}$ \\
\hline $\mathrm{Q}_{\mathrm{i}}$ & 0.0163 & 0.0827 & $\mathrm{~g} . \mathrm{bar}^{-1}$ \\
\hline $\mathrm{R}_{\mathrm{i}}$ & 0.1020 & 0.0105 & $\mathrm{~g} \cdot \mathrm{bar}^{-1}$ \\
\hline$\gamma_{\mathrm{i}}{ }^{\alpha}$ & 0.9346 & 0.2034 & - \\
\hline$h_{i}^{e x}$ & -3.39 & +28.23 & $\mathrm{~kJ} . \mathrm{mol}^{-1}$ \\
\hline
\end{tabular}

By comparing with Table 4, we clearly see a strong dependence of the infinite dilution activity coefficients on temperature, with an increase with temperature for $\mathrm{CO}_{2}$ and a decrease for $\mathrm{CH}_{4}$. The data at different temperatures can be used to evaluate 
thermodynamic quantities that are essentially excess partial molar enthalpies, and may be assimilated to activation energies for the activity coefficients:

$$
\left(\frac{\partial \ln \gamma_{i}}{\partial T}\right)_{P, x}=\frac{\partial}{\partial T}\left(\frac{\bar{g}_{i}^{e x}}{R T}\right)_{P, x}=-\frac{\bar{h}_{i}^{e x}}{R T^{2}}
$$

Assuming either that $\bar{h}_{i}^{e x}$ is a constant or that the temperature interval is small, this equation may be integrated into:

$$
\ln \gamma_{i}\left(T_{2}\right)-\ln \gamma_{i}\left(T_{1}\right)=\frac{\bar{h}_{i}^{e x}}{R}\left[\frac{1}{T_{2}}-\frac{1}{T_{1}}\right]
$$

The measured values of $\gamma_{i}^{\alpha}$ may be used to evaluate $\bar{h}_{i}^{e x}$. Their order of magnitude is given in Table 9. When assumed constant in a range, they can be used for interpolation or moderate extrapolation.

\section{Comparison with earlier data.}

As mentioned in the introduction, a few earlier studies concern co-adsorption of carbon dioxide and methane on a activated carbon, and its description using activity coefficients. The data of [Buss, 1995] show activity coefficients larger than unity over the whole composition range, for an activated carbon with large pores and a relatively homogeneous surface. The data of [Van der Vaart et al., 2000] on Norit RB1 should be more in agreement with the present findings, since the isotherms for the pure components at $1 \mathrm{bar}$, the total mass adsorbed and the co-adsorbed concentrations of $\mathrm{CO} 2$ are quite close to that found here. Nevertheless, the activity coefficients are significantly different. The Wilson parameters as fitted by these authors are $\Lambda_{12}=2.8$ and $\Lambda_{21}=0.018$ (to compare to our values $\Lambda_{12}=0.0071 ; \Lambda_{21}=6.1111$ ) corresponding to $\gamma_{1}{ }^{\infty}=0.954$ and $\gamma_{2}{ }^{\infty}=9.18$. In particular, the large value of the activity coefficient for $\mathrm{CH} 4$ contradicts our small value of 0.442 .

We are tempted to explain this difference by the fact that the limiting activity coefficients do not enter at all in the Van der Vaart calculations, and that their Wilson fit is somewhat rough, whereas they are the fundamental data in our approach, and their values entirely determines the shapes of the Wilson plot. The qualitative difference is that in our case, the activity is practically always smaller than that of an ideal bulk mixture, whereas the Van der Vaart values shows a very high activity of methane at low concentrations. These features should probably be explained on physical grounds.

\section{CONCLUSION}

Let us discuss critically the methodology proposed in the light of the examples and results presented.

Experimental simplicity, practical convenience, theoretical complexity. 
The main interest of this approach is its experimental simplicity. Besides the single component isotherms, only two measurements are strictly necessary, at the limits of large dilution, to obtain the two basic parameters, the $\gamma^{\infty}$. But such measurements are rather difficult and on the other hand, the complete gravimetric curve is convenient to obtain. The latter is thus used for testing the experimental conditions (incremental and decremental curves should coincide), for extrapolation to infinite dilution, as a verification of the overall fit of the model, and also to discriminate between activity models. Choosing a priori a simple model for the activity coefficients, such as Margules or Van Laar, suffices to construct a reasonable estimate of the complete binary isotherm. The theoretical complexity has to be faced only once: once the formulae are established, the calculations and algorithms are quite straightforward.

\section{Model versus measure.}

Let us first recall that the approach proposed aims at building a thermodynamic model of the equilibria capable of representation, of extrapolation, of multi-component extension, and of incorporation in a process simulator. Model building includes parameter determination and model discrimination. Measuring the total mass adsorbed in the binary system (together with the single component isotherms) gives sufficient information for this purpose, under certain assumptions. It is not an information equivalent to measuring the individual adsorbed quantities, and this approach should not be considered as an alternative to full measuring techniques.

Thermodynamic assumptions, accuracy, versatility and coherence.

The versatility and fitting power of the models used here are restricted by two factors:

- the fact that two adjusted parameters only are introduced, and that we want them uniquely determined by the measured data;

- the fact that the models are thermodynamically coherent, in the sense of satisfying all thermodynamic constraints coherent with the assumptions (such as GibbsDuhem), and the assumptions themselves are not thermodynamically prohibited.

These factors contribute to convenience of use and to predictive power, which in a sense we pay for in loss of versatility and fitting power. If more accuracy and more versatility are sought, more parameters are needed. Unicity of these parameters and thermodynamic coherence can only be preserved if more measured data are used in the framework of an extended model. We shall show how this can de done in a forthcoming paper.

\section{Unicity of the $\gamma^{\infty}$ and model dependence.}

The fact that we get the $\gamma^{\infty}$ from one experimental information only at each end of the composition range stems from the thermodynamic constraints and from choosing a two parameter model. Any additional measurement is redundant and must be reconciliated with the above. The analytical and linear character of the expressions for the $\gamma^{\circ}$ (Equations 4041 or 50-51) ensures that the solutions for the $\gamma^{\infty}$ corresponding to given experimental data are unique (contrarily to any global fitting method). As mentioned above, they are also model-independent for the RAS models, but not for the SPD models.

The different models for the composition dependence of the $\gamma$ can be discriminated only through a numerical best fit criterion, using for example the full adsorbed mass curve, not through a thermodynamic criterion. The model of activity coefficient variation is therefore not unique. Other models are available than those used here. For example the UNIQUAC approach [Abrams and Prausnitz, 1975] also involves two parameters that can be determined in this way, but together with a number of chemical parameters obtained 
from tables. The Non-Random Two-Liquids model [Renon and Prausnitz, 1968] involves 3 parameters, and would require a global fitting approach.

Just as the Adsorbed Solution Theory, the approach proposed is in principle independent of the model chosen to represent the single-component isotherms. In our specific example, we have used Langmuir isotherms because they turn out to represent reasonably our data, and in addition, are convenient for calculations (see Appendix ). But any other model fitting well the isotherm data would do, and as a matter of fact, no explicit model at all is needed. Since the quality of the binary representation is sensitive to the quality of the single component representation, if accurate experimental data are available, it may be better to use a table of measured values with a suitable interpolation rule rather than an analytical model.

\section{Extensions and perspectives.}

A number of open questions and of potential developments are left for future work, concerning the experimental procedure as well as the theory. Among these, we should like to mention: use of temperature programming to obtain conveniently temperature dependent data; interpolation between different pressures and temperatures, as envisaged through Equation 63; obtain binary data at different total pressures using an inert gas; generate approximate but consistent analytical expressions for the co-adsorption curves; extend the approach to heterogeneous surfaces; incorporate the binary co-adsorption results into a general model of multi-component column operation.

But the main point seems the need to extend the approach to models accounting for spreading pressure dependence and with more parameters, as suggested by Myers' work [Myers, 1989]. Besides being more in coherence with the full non-ideal adsorbed solution theory, one would certainly gain in both fitting power and predictive power. While this paper was being reviewed, we have actually set the bases for such a development, introducing two additional parameters, obtained independently from data at two different pressures. This will be presented in a forthcoming paper.

\section{ACKNOWLEDGMENTS}

This work was carried out in the framework of the research program CARBMAT, supported by the French Ministry of Research, under the coordination of the Company L'Air Liquide, Centre de Recherches Claude-Delorme, Les-Loges-en-Josas, France. The authors are grateful to the Company for financing the thesis of K.Bonnot and for providing adsorbents and data, and to the researchers of the Centre de Recherches who participated in the program, for fruitful discussion, constructive criticism and efficient coordination. We specially thank Dr Lianming SUN for starting this cooperation and for his scientific advice. We would also like to thank the researchers of Institut des Matériaux et Procédés du CNRS in Perpignan, France, as co-participants to the program. 


\section{APPENDIX}

\section{Example of Langmuir single-component isotherms.}

In this case, a large part of the calculations may be carried out analytically, and therefore it constitutes a good illustration. Letting:

$$
q_{i}=\frac{q_{i m} k_{i} p_{i}}{1+k_{i} p_{i}}
$$

the derivative is

$$
\frac{d q_{i}}{d p_{i}}=\frac{q_{i m} k_{i}}{\left(1+k_{i} p_{i}\right)^{2}}
$$

and the spreading pressure or rather the loading $\psi$ is obtained from:

$$
\Psi=\int_{0}^{p_{i}} \frac{q_{i}}{p_{i}} d p=q_{i m} \ln \left(1+k_{i} p_{i}\right)
$$

For a given loading $\psi$, Eq. A3 may be inverted to yield :

$$
p_{i}=\frac{-1}{k_{i}}\left[1-\exp \left(\frac{\psi}{q_{i m}}\right)\right]
$$

In mixture adsorption, the value of spreading pressure or loading is common to all components, and therefore, for a given value of $\psi$, the fictitious pressures $\mathrm{P}_{\mathrm{i}}{ }^{*}$ of all components must have values that satisfy Equation A3 or A4.

The "curvature parameters" $\xi_{\mathrm{i}}$ are given by Eq. A5 below and may be computed, using Eqs A1 and A2.

$$
\xi_{i}^{*}=\frac{P_{i}^{*}}{q_{i}}\left(\frac{d q_{i}}{d p_{i}}\right)_{p=P_{i}^{*}}=\frac{1}{1+k_{i} P_{i}^{*}}
$$

The limiting values at infinite dilution of component 1 may be calculated by observing that when $\mathrm{x}_{1} \rightarrow 0, \mathrm{p}_{2} \rightarrow \mathrm{P}, \mathrm{P}_{2}^{*} \rightarrow \mathrm{P}$ and $\mathrm{q}_{2} \rightarrow \mathrm{q}_{2}(\mathrm{P})$. Then Eqn. A3 is written twice for $\mathrm{i}=1$ and 2 , and the right hand sides are equated and solved for $\mathrm{P}_{1}{ }^{*}$ lim to give: 


$$
\begin{gathered}
P_{1 \lim }^{*}=\frac{1}{k_{1}}\left[-1+\left[1+k_{1} P\right] \frac{q_{2 m}}{q_{1 m}}\right] \\
q_{1 \lim }^{*}=q_{1}\left(P_{1 \lim }^{*}\right)=\frac{q_{1 m} k_{1} P_{1 \lim }^{*}}{1+k_{1} P_{1 \lim }^{*}}
\end{gathered}
$$

The limit value $\mathrm{q}_{1 \text { lim }}^{*}$ necessary to use Eqns.23, 28, 29 is then obtained from the isotherm Eqn.A1:

Finally, Eqn.A5 is particularized for $\mathrm{i}=2$, with $\mathrm{P}_{2}{ }^{*}=\mathrm{P}$ :

$$
\xi_{2 \lim }^{*}=\frac{1}{1+k_{2} P}
$$

All quantities involved in Eqns. 28 and 29 have now an explicit algebraic expression, calculable from the single component isotherms, and therefore the "theoretical IAS value" of $\mathrm{dm}_{\mathrm{t}} / \mathrm{dp}_{1}$ may be calculated, and compared to the measured value. Of course, the same procedure is used for infinite dilution of component 2. If the discrepancy between measured and calculated values of $\mathrm{dm}_{t} / \mathrm{dp}_{1}$ justifies it, $\gamma_{i}^{\infty}$ is used as adjusting parameter in Eqns 38-40, all other quantities being constant. With two values of $\gamma^{\infty}$ and a classical two parameter model of activity coefficients, the RAS approach is then completely identified. If one wants to test the two parameter SPD model, Eqn.60 is used with $\psi_{\text {lim }}$ calculated from Eqn. A3 as

$$
\psi_{\lim }\left(\mathrm{x}_{1} \rightarrow 0\right)=\mathrm{q}_{2 \mathrm{~m}} \ln \left(1+\mathrm{k}_{2} \mathrm{P}\right)
$$

The constants $\mathrm{B}$ and $\mathrm{C}$ are identified and reintroduced into Eqn.54, completing the identification of this model. 


\section{NOMENCLATURE}

\begin{tabular}{|c|c|c|}
\hline$a_{i}$ & molar surface area of species i & {$\left[\mathrm{m}^{2} \mathrm{~mol}^{-1}\right]$} \\
\hline A & specific surface area of adsorbent & {$\left[\mathrm{m}^{2} \mathrm{~kg}^{-1}\right]$} \\
\hline B & coefficient in ISAC model (Eq.53-60) & {$\left[\mathrm{J} . \mathrm{mol}^{-1}\right]$} \\
\hline $\mathrm{C}$ & coefficient in ISAC model (Eq.53-60) & {$\left[\mathrm{kg} \cdot \mathrm{mol}^{-1}\right]$} \\
\hline g & molar Gibbs energy & {$\left[\mathrm{J}^{\mathrm{mol}}{ }^{-1}\right]$} \\
\hline$g^{\text {ex }}$ & excess molar Gibbs energy in adsorbed phase & {$\left[\mathrm{J} . \mathrm{mol}^{-1}\right]$} \\
\hline $\mathrm{k}_{\mathrm{i}}$ & coefficient in Langmuir isotherm (Eq. 60) & {$\left[\mathrm{bar}^{-1}\right]$} \\
\hline $\mathrm{G}^{\mathrm{ex}}$ & excess Gibbs energy of adsorbed phase & {$[\mathrm{J}]$} \\
\hline $\mathrm{m}$ & coefficient in Flory-Huggins model & {$[-]$} \\
\hline $\mathrm{m}_{\mathrm{a}}$ & mass of clean adsorbent sample & {$[\mathrm{kg}]$} \\
\hline $\mathrm{m}_{\mathrm{i}}$ & adsorbed mass of component i & {$[\mathrm{kg}]$} \\
\hline $\mathrm{m}_{\mathrm{t}}$ & total adsorbed mass & {$[\mathrm{kg}]$} \\
\hline M & average molar mass of the gas mixture & {$\left[\mathrm{kg} \cdot \mathrm{mol}^{-1}\right]$} \\
\hline $\mathrm{M}_{\mathrm{i}}$ & molar mass of component I & {$\left[\mathrm{kg} \cdot \mathrm{mol}^{-1}\right]$} \\
\hline$M_{2}^{\prime R A S}$ & quantity defined in Eq. 39 & {$\left[\mathrm{~kg} \cdot \mathrm{mol}^{-1}\right]$} \\
\hline$M_{2}^{\prime S P D}$ & quantity defined in Eq. 51 & {$\left[\mathrm{~kg} \cdot \mathrm{mol}^{-1}\right]$} \\
\hline $\mathrm{n}$ & number of moles of the mixture & {$[\mathrm{mol}]$} \\
\hline $\mathrm{P}_{\mathrm{i}}$ & partial pressure of component I in gas & {$[\mathrm{Pa}]$ or $[\mathrm{bar}]$} \\
\hline $\mathrm{P}$ & total pressure & {$[\mathrm{Pa}]$ or $[\mathrm{bar}]$} \\
\hline $\mathrm{P}_{\mathrm{i}}^{*}$ & $\begin{array}{l}\text { fictitious pressure of component } \mathrm{i} \text { in Adsorbed Solution } \\
\text { theory }\end{array}$ & {$[\mathrm{Pa}]$ or $[\mathrm{bar}]$} \\
\hline $\mathrm{q}_{\mathrm{i}}$ & concentration of adsorbed component $\mathrm{i}$ & $\mathrm{g}^{-1}$ adsorbent \\
\hline $\mathrm{q}_{\mathrm{m}}$ & maximal adsorbed concentration in Langmuir isotherm & {$\left[\mathrm{mol} . \mathrm{kg}^{-1}\right]$} \\
\hline $\mathrm{q}_{\mathrm{t}}$ & total concentration in adsorbed phase & {$\left[\mathrm{mol} . \mathrm{kg}^{-1}\right]$} \\
\hline Q & coefficient in Eq.40, defined by Eq.41 & {$\left[\mathrm{kg} \cdot \mathrm{bar}^{-1}\right]$} \\
\hline $\mathrm{R}$ & coefficient in Eq.40, defined by Eq. 41 & {$\left[\mathrm{~kg} \cdot \mathrm{bar}^{-1}\right]$} \\
\hline $\mathrm{R}$ & gas constant & {$\left[\mathrm{J} \cdot \mathrm{mol}^{-1} \cdot \mathrm{K}^{-1}\right]$} \\
\hline$S^{e x}$ & excess entropy of mixing in adsorbed phase & {$\left[\mathrm{J} . \mathrm{K}^{-1}\right]$} \\
\hline $\mathrm{T}$ & temperature & {$[\mathrm{K}]$} \\
\hline $\mathrm{V}^{\mathrm{ex}}$ & volume of mixing in the adsorbed phase & {$\left[\mathrm{m}^{\frac{1}{3}}\right]$} \\
\hline $\mathrm{x}_{\mathrm{i}}$ & mole fraction of component $\mathrm{I}$ in adsorbed phase & {$[-]$} \\
\hline $\mathrm{y}_{\mathrm{i}}$ & mole fraction of component $\mathrm{I}$ in gas phase & {$[-]$} \\
\hline
\end{tabular}

\section{Greek letters}

\begin{tabular}{|c|c|c|}
\hline$\alpha$ & coefficient in Van Laar model & [-] \\
\hline$\alpha_{\mathrm{i}}$ & coefficient in Margules model & {$[-]$} \\
\hline$\beta$ & coefficient in Van Laar model & {$[-]$} \\
\hline$\beta_{\mathrm{i}}$ & coefficient in Margules model & {$[-]$} \\
\hline$\gamma_{\mathrm{i}}$ & activity coefficient of component $\mathrm{i}$ in adsorbed phase & {$[-]$} \\
\hline$\Delta$ & defined by Eq. 35 or 47 & {$[-]$} \\
\hline$\Delta_{\mathrm{i}}$ & quantity defined in Eq.46 & {$[-]$} \\
\hline$\Delta^{\prime}{ }_{2}$ & quantity defined in Eq.52 & {$\left[\mathrm{kg} \cdot \mathrm{mol}^{-1}\right]$} \\
\hline$\Lambda_{12}, \Lambda_{21}$ & parameters of Wilson model & {$[-]$} \\
\hline$\chi$ & parameter of Flory-Huggins model & {$[-]$} \\
\hline$\Pi$ & spreading pressure of adsorbed phase & {$\left[\mathrm{J} . \mathrm{m}^{-2}\right]$ or $\left[\mathrm{N} \cdot \mathrm{m}^{-1}\right]$} \\
\hline & loading, or compressibility factor of adsorbed phase & {$\left[\mathrm{mol} . \mathrm{kg}^{-1}\right]$} \\
\hline & concavity parameter of isotherm of component $i$, defir & y Eq. $24[-]$ \\
\hline
\end{tabular}




\section{Subscripts}

1,2

designate components $1\left(\mathrm{CO}_{2}\right)$ and $2\left(\mathrm{CH}_{4}\right)$

$\mathrm{i}, \mathrm{j}$

designate components

lim designates limiting values, when the concentration of one component tends toward zero

$\mathrm{t}$

designates total quantities, sum of the quantities relative to the two components

\section{Superscripts}

ex

$*$

○

$\infty$

$-$ excess properties

properties of single component equilibria

initial state

infinite dilution

overline: partial molar quantities 


\section{REFERENCES}

Abrams D.S. and Prausnitz J.M., "Statistical thermodynamics of liquid mixtures: a new expression for excess Gibbs energy of partly or completely miscible systems", A.I.Ch.E.J., 21, 116 (1975)

Buss E., "Gravimetric measurements of binary equilibria of Methane-Carbon Dioxide mixtures on activated carbon", Gas Sep.Purif., 9, 189-197 (1995)

Costa E., Sotelo J.L., Calleja G., and Marron C., "Adsorption of binary and ternary hydrocarbon gas mixtures on activated carbon: experimental determination and theoretical prediction of the ternary equilibrium data", A.I.Ch.E.J., 27, 5-12 (1981)

Do D.D., Adsorption Analysis: Equilibrium and Kinetics, Imperial College Press, London (1998)

Dreisbach F., Seif R., Lösch H., and Keller J.U., "Gravimetric measurement of adsorption equilibria of gas mixtures $\mathrm{CO} / \mathrm{H} 2$ with a magnetic suspension balance", p.255-262, Proc. $7^{\text {th }}$ Conf. Fundamentals of Adsorption, K.Kaneko and Y.Hanzawa, Eds., J.K International, Chiba, Japan (2001)

Friedrichs R.O., and Mullins J.C., "Adsorption equilibria of binary hy drocarbon mixtures on homogeneous carbon black at $25^{\circ} \mathrm{C}$ ", Ind.Eng.Chem.Fundam. 11, 439-445 (1972)

Herington E.F., "A thermodynamic test for the internal consistency of experimental data on volatility ratios", Nature, 160, 610-611 (1947)

Kabir H., Grevillot G., and Tondeur D., "Equilibria and activity coefficients for nonideal adsorbed mixtures from perturbation chromatography", Chem.Eng.Sci., 53 (Nº) 1639-1654 (1998)

Keller J.U., Dreisbach F., Rave H., Staudt R., and Tomalla M., "Measurement of gas mixture adsorption equilibria of natural gas compounds on microporous adsorbents", adsorption, 5, 199-214 (1999)

Kopatsis A., Salinger A. and Myers A.L., "Thermodynamics of solutions with solvent and solute in different pure states" A.I.Ch.E.J., 34, 1275-1286 (1988)

Myers A.L., and Prausnitz J.M., "Thermodynamics of mixed gas adsorption”, A.I.Ch.E.J., 11, 121-127 (1965)

Myers A.L., Minka C., and Ou D.Y., "Thermodynamic properties of adsorbed mixtures of benzene and cyclohexane on graphitised carbon and activated charcoal at $30^{\circ} \mathrm{C}$ ", A.I.Ch.E.J., 28, 97-102 (1982)

Myers A.L., "Gravimetric measurement of adsorption from binary gas mixtures", Pure \& Appl.Chem., 61, 1949-1953 (1989)

Renon H. and Prausnitz J.M., A.I.Ch.E.J. 14, 135 (1968) 
Sandler S.I., Chemical and Engineering Thermodynamics, Wiley, New-York (1999)

Siperstein F., Gorte R.J., Myers A.L., "Measurement of excess functions of binary gas mixtures adsorbed in zeolites by adsorption calorimetry", Adsorption, 5, 169-176 (1999]

Talu O., and Zwiebel I., "Multicomponent adsorption equilibria of non-ideal mixtures", A.I.Ch.E.J., 32, 1263- (1986)

Van der Vaart R., Huiskes C., Bosch H., and Reith T., "Single and mixed gas adsorption equilibria of carbon dioxide/methane on activated carbon", Adsorption, 6, 313-323 (2000)

Van Ness H.C., “Adsorption of gases on solids”, I\&EC Fundam., 8 (№3) 464-473 (1969) 
Table 1:

Parameters of the Langmuir representation for $\mathrm{CO} 2$ and $\mathrm{CH} 4$ isotherms on Norit $\mathrm{RB} 2$.at $\mathrm{T}=295^{\circ} \mathrm{K}$ and $\mathrm{P}=1.01$ bar

\begin{tabular}{|c|c|c|c|}
\hline \multicolumn{2}{|c|}{$\begin{array}{c}\text { Component } \\
\text { Temperature }\end{array}$} & $1=\mathrm{CO} 2$ & $2=\mathrm{CH} 4$ \\
\hline $295^{\circ} \mathrm{K}$ & $\begin{array}{c}\mathrm{q}_{\mathrm{m}} \\
\left(\mathrm{mol}_{\mathrm{kg}}{ }^{-1}\right)\end{array}$ & 7.94 & 4.87 \\
\cline { 2 - 4 } & $\begin{array}{c}\mathrm{k} \\
\left(\mathrm{bar}^{-1}\right)\end{array}$ & 0.496 & 0.389 \\
\hline $314^{\circ} \mathrm{K}$ & $\begin{array}{c}\mathrm{q}_{\mathrm{m}} \\
\left(\mathrm{mol}^{-1} \mathrm{~kg}^{-1}\right)\end{array}$ & 6.48 & 4.59 \\
\cline { 2 - 4 } & $\begin{array}{c}\mathrm{k} \\
\left(\mathrm{bar}^{-1}\right)\end{array}$ & 0.358 & 0.182 \\
\hline
\end{tabular}

Table 2

Characteristic parameters of adsorption of $\mathrm{CO} 2$ and $\mathrm{CH} 4$ at $\mathrm{T}=295^{\circ} \mathrm{K}$ and $\mathrm{P}=1.01 \mathrm{bar}$

\begin{tabular}{|c|c|c|c|}
\hline Component $\rightarrow$ & $1=\mathrm{CO} 2$ & $\left(\mathrm{x}_{1} \rightarrow 0\right)$ & $2=\mathrm{CH} 4 \quad\left(x_{2} \rightarrow 0\right)$ \\
\hline $\begin{array}{c}\psi_{\mathbf{i} \lim } \\
\mathrm{mol.kg}^{-1}\end{array}$ & $\psi_{1 \lim }=$ & 1.452 & $\psi_{2 \lim }=2.914$ \\
\hline $\begin{array}{c}\mathbf{P}^{*} \lim \\
\text { bar }\end{array}$ & $\mathrm{P}^{*}{ }_{1 \lim }=$ & 0.458 & $\mathrm{P}^{*}{ }_{2 \lim }=2.397$ \\
\hline $\begin{array}{l}\mathbf{q}^{*}\left(\mathbf{P}_{\lim }\right) \\
\text { mol.kg } \\
\end{array}$ & $\mathrm{q}^{*}\left(\mathrm{P}_{11 \mathrm{im}}\right)$ & $=1.352$ & $\mathrm{q}_{2}\left(\mathrm{P}_{2 \lim }\right)=2.213$ \\
\hline $\begin{array}{c}\mathbf{q}^{*}(\mathbf{P}) \\
\mathrm{mol}^{-k^{-1}}\end{array}$ & $\mathrm{q} *_{1}(\mathrm{P})=$ & 2.491 & $\mathrm{q}^{*}(\mathrm{P})=1.270$ \\
\hline$\xi$ & $\xi_{1 \lim }=$ & 1.196 & $\xi_{2 \lim }=$ \\
\hline
\end{tabular}

Table 3

Experimental and IAS values of $\mathrm{dm}_{\mathrm{t}} / \mathrm{dp}$ at the composition limits $\left(295^{\circ} \mathrm{K}\right)$

\begin{tabular}{|c|c|c|}
\hline Values of $\left(\mathbf{d m}_{t} / d p_{1}\right) \quad\left(g^{\prime} \cdot b^{-1}\right)$ & $\left(d m / d p_{i}\right)$ measured & $\left(\mathrm{dm} / \mathrm{dp}_{\mathrm{i}}\right)^{\mathrm{IAS}}$ calc (Eq.28) \\
\hline $\mathrm{x}_{1}=\mathrm{x}_{\mathrm{CO} 2} \rightarrow 0$ & $\left(\mathrm{dm} / \mathrm{dp}_{1}\right)=0.14846$ & $\left(\mathrm{dm} / \mathrm{dp}_{1}\right)=0.12109$ \\
\hline $\mathrm{x}_{2}=\mathrm{x}_{\mathrm{CH} 4} \rightarrow 0$ & $\left(\mathrm{dm} / \mathrm{dp}_{2}\right)=-0.08210$ & $\left(\mathrm{dm} / \mathrm{dp}_{2}\right)=-0.10641$ \\
\hline Values of $\widetilde{M}$ (Eq.29) (kg.mol $\left.{ }^{-1}\right)$ & $\tilde{M}_{1}=0.1216$ & $\tilde{M}_{2}=-0.0011$ \\
\hline
\end{tabular}


Table 4

Calculation of infinite dilution activity coefficients in adsorbed phase from the measured limit values of $\mathrm{dm}_{\mathrm{t}} / \mathrm{dp}$

\begin{tabular}{|c|c|c|}
\hline $\begin{array}{c}\text { Infinite dilution } \\
\text { activity coefficients }\end{array}$ & $\begin{array}{c}\mathbf{C O 2} \\
\mathbf{x}_{\mathbf{1}}=\mathbf{x}_{\mathbf{C O 2}} \rightarrow \mathbf{0}\end{array}$ & $\begin{array}{c}\mathbf{C H 4} \\
\mathbf{x}_{\mathbf{2}}=\mathbf{x}_{\mathbf{C H} 4} \rightarrow \mathbf{0}\end{array}$ \\
\hline Coefficient Q (Eq.40) & 0.0359 & 0.1256 \\
\hline Coefficient R (Eq.40) & 0.1970 & 0.0192 \\
\hline$\gamma \propto$ & $\gamma_{1} \propto=0.8515$ & $\gamma_{2} \propto=0.4417$ \\
\hline $\operatorname{Ln} \gamma \propto$ & -0.16075 & -0.81712 \\
\hline
\end{tabular}

Table 6

Numerical values of model parameters for activity coefficients

$\mathrm{CO} 2+\mathrm{CH} 4$ on Norit $\mathrm{RB} 2$ at $295^{\circ} \mathrm{K}$

\begin{tabular}{|l|l|l|l|l|}
\hline Wilson & Van Laar & Flory-Huggins & Margules & ISAC \\
\hline & & & $\alpha_{1}=-1.4733$ & \\
$\Lambda_{12}=0.00708$ & $\alpha=-0.1608$ & $\mathrm{~m}=3.396$ & $\beta_{1}=1.3125$ & $\mathrm{~B} / \mathrm{RT}=0.05310$ \\
$\Lambda_{21}=6.11111$ & $\beta=-0.8170$ & $\chi=0.3563$ & $\alpha_{2}=0.4955$ & \\
& & & $\beta_{2}=-1.3125$ & $\mathrm{C}=-0.95951$ \\
\hline
\end{tabular}

Table 7

Deviation of models from experiment for the total adsorbed mass $\left(295^{\circ} \mathrm{K}\right)$

\begin{tabular}{|c|c|c|c|c|c|c|}
\hline $\begin{array}{c}\text { Model } \rightarrow \\
\text { Deviation\% }\end{array}$ & IAS & Wilson & Van Laar & Flory-H. & Margules & ISAC \\
\hline Standard deviation & 13.21 & 5.15 & 2.15 & 3.86 & 0.79 & 2.91 \\
\hline Mean deviation & 11.52 & 3.33 & 1.80 & 3.24 & 0.68 & 2.24 \\
\hline
\end{tabular}


Table 8

Data and parameters for the $\mathrm{CO} 2-\mathrm{CH} 4$ isotherm at $293^{\circ} \mathrm{K}, \mathrm{P}=2.06$ bar

\begin{tabular}{|l|l|l|l|}
\hline $\mathrm{i}$ & $1=\mathrm{CO} 2$ & $2=\mathrm{CH} 4$ & units \\
\hline$\psi_{\lim }$ & 2.598 & 5.122 & $\mathrm{~mol} . \mathrm{kg}^{-1}$ \\
\hline $\mathrm{P}_{\lim }$ & 0.884 & 5.578 & bar \\
\hline $\mathrm{q}_{\lim }(\mathrm{P})$ & 3.862 & 2.031 & $\mathrm{~mol} . \mathrm{kg}^{-1}$ \\
\hline $\mathrm{q}_{\lim }\left(\mathrm{P}_{\lim }\right)$ & 2.263 & 3.205 & $\mathrm{~mol} . \mathrm{kg}^{-}$ \\
\hline$\xi_{\lim }$ & 1.377 & 1.092 & - \\
\hline$\left(\mathrm{dm} / \mathrm{dp}_{\mathrm{i}}\right)_{\mathrm{xi}=0}$ & 0.1058 & -0.0490 & $\mathrm{~g} \cdot \mathrm{bar}^{-1}$ \\
\hline $\mathrm{Q}_{\mathrm{i}}$ & 0.0167 & 0.1069 & $\mathrm{~g}_{\mathrm{bar}}$ \\
\hline $\mathrm{R}_{\mathrm{i}}$ & 0.1049 & 0.0158 & $\mathrm{~g} \cdot \mathrm{bar}^{-1}$ \\
\hline$\gamma_{\mathrm{i}}^{\alpha}$ & 0.856 & 0.273 & - \\
\hline
\end{tabular}

Table 9.

Data and parameters for the $\mathrm{CO} 2-\mathrm{CH} 4$ isotherm at $314^{\circ} \mathrm{K}, \mathrm{P}=1.01$ bar

\begin{tabular}{|l|l|l|l|}
\hline $\mathrm{i}$ & $1=\mathrm{CO} 2$ & $2=\mathrm{CH} 4$ & units \\
\hline $\mathrm{q}_{\mathrm{m}}{ }^{*}$ & 6.48 & 4.59 & $\mathrm{~mol} \cdot \mathrm{kg}^{-1}$ \\
\hline $\mathrm{b}_{\mathrm{i}}$ & 0.358 & 0.182 & $\mathrm{bar}^{-1}$ \\
\hline$\psi_{\lim }$ & 0.737 & 1.967 & $\mathrm{~mol} \cdot \mathrm{kg}^{-1}$ \\
\hline $\mathrm{P}_{\lim }$ & 0.347 & 3.123 & $\mathrm{bar}$ \\
\hline $\mathrm{q}_{\lim }(\mathrm{P})$ & 1.718 & 0.690 & $\mathrm{~mol} \cdot \mathrm{kg}^{-1}$ \\
\hline $\mathrm{q}_{\lim }\left(\mathrm{P}_{\lim }\right)$ & 0.706 & 1.624 & $\mathrm{~mol} \cdot \mathrm{kg}^{-}$ \\
\hline$\xi_{\lim }$ & 1.141 & 1.539 & - \\
\hline$\left(\mathrm{dm} / \mathrm{dp}_{\mathrm{i}}\right)_{\mathrm{xi}=0}$ & 0.0929 & -0.0312 & $\mathrm{~g} \cdot \mathrm{bar}^{-1}$ \\
\hline $\mathrm{Q}_{\mathrm{i}}$ & 0.0163 & 0.0827 & $\mathrm{~g} \cdot \mathrm{bar}^{-1}$ \\
\hline $\mathrm{R}_{\mathrm{i}}$ & 0.1020 & 0.0105 & $\mathrm{~g} \cdot \mathrm{bar}^{-1}$ \\
\hline$\gamma_{\mathrm{i}}{ }^{e x}$ & 0.9346 & 0.2034 & - \\
\hline$h_{i}^{e x}$ & -3.39 & +28.23 & $\mathrm{~kJ} \cdot \mathrm{mol}^{-1}$ \\
\hline
\end{tabular}


Figure 1 Experimental set-up of microbalance to measure adsorption equilibria

$\begin{array}{ll}1,2 & \text { Mass Flow Regulators } \\ 3 & \text { Heating element } \\ 4 & \text { Sample cell } \\ 5 & \text { Thermostated envelope } \\ 6 & \text { Temperature sensor } \\ 7 & \text { Balance } \\ 8 & \text { Electro-magnet } \\ 9 & \text { Permanent magnet } \\ 10 & \text { Measuring cell } \\ 11 & \text { Pressure sensor } \\ 12 & \text { Gas outlet, towards waste }\end{array}$

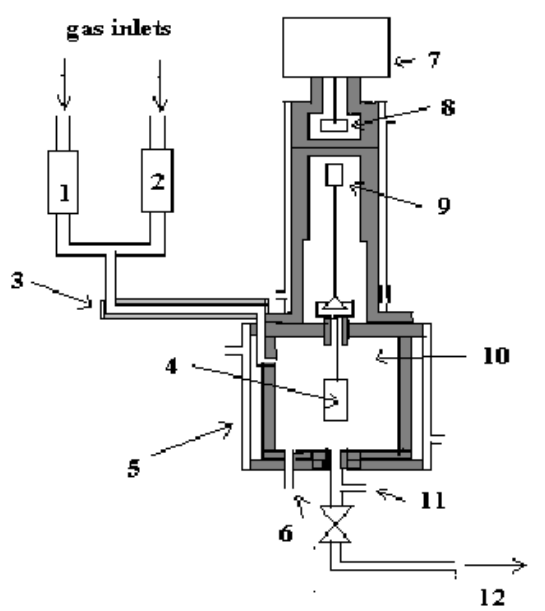




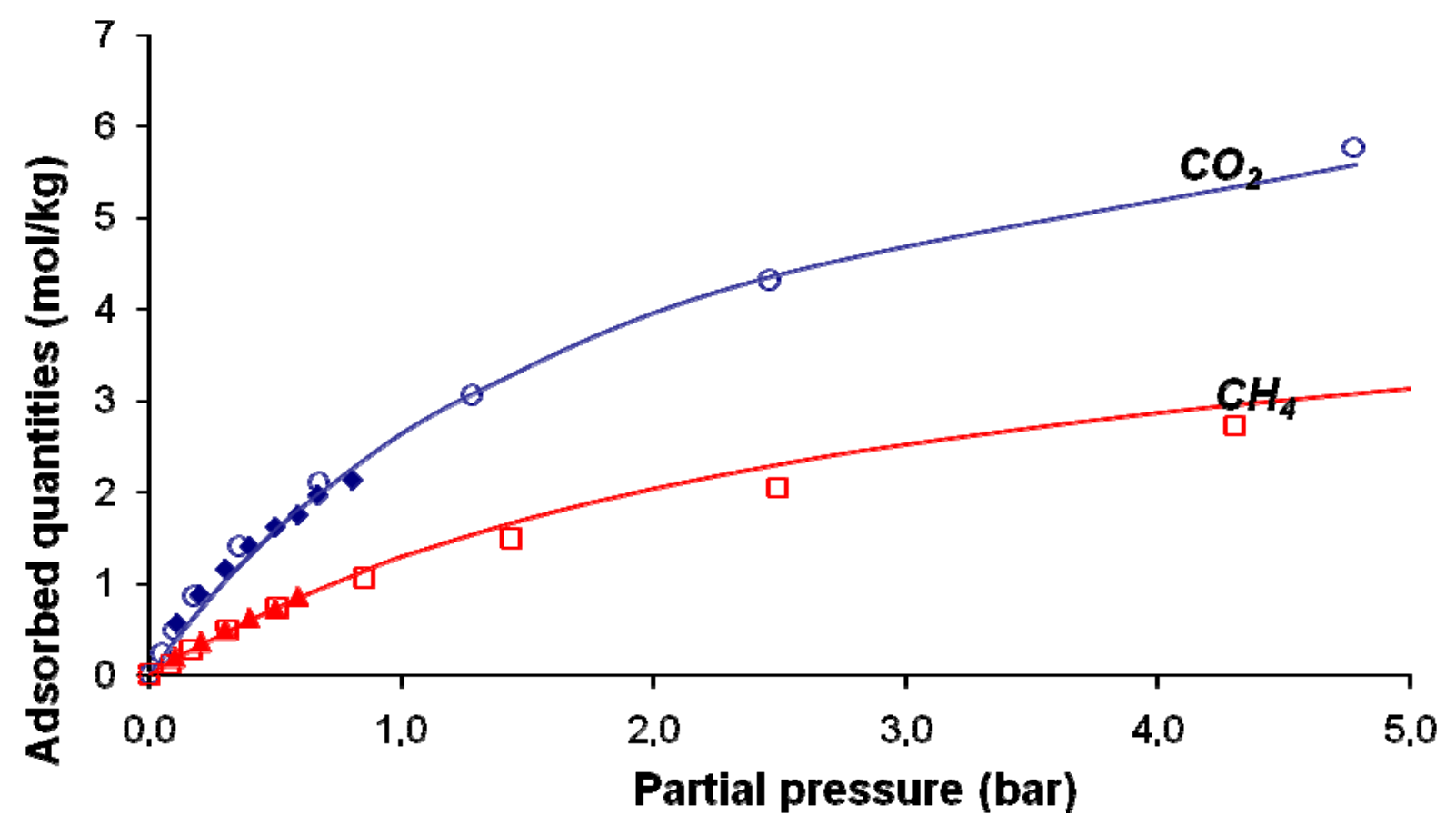

Figure 2 Adsorption isotherms of carbon dioxide and methane on Norit RB2 activated carbon at $295^{\circ} \mathrm{K}$

- $\Delta$ Experimental values below 1 bar obtained by the flow method

- $\square \quad$ Experimental points provided by L'Air Liquide

Langmuir fit with parameters of Table 1 


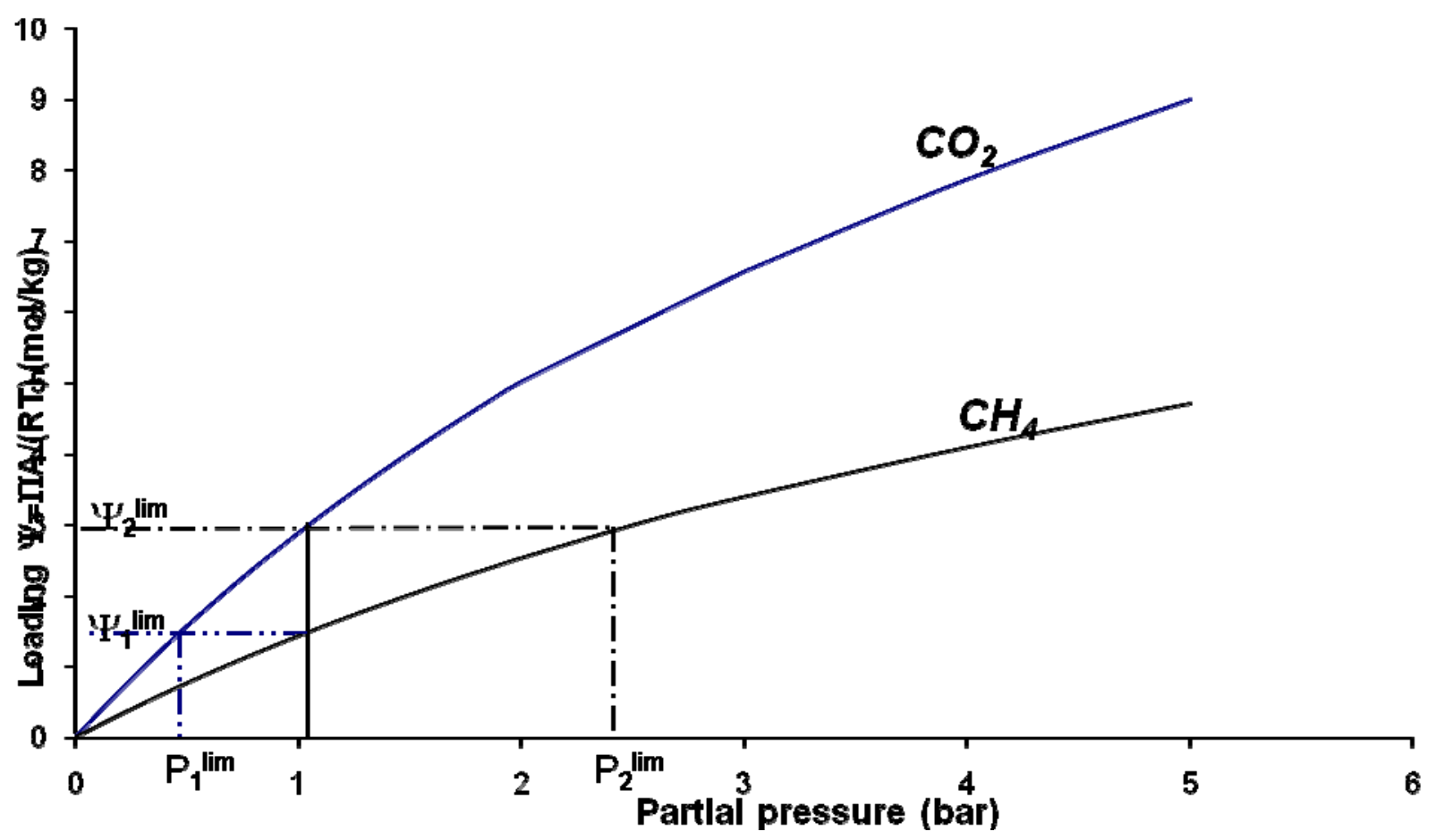

Figure 3 Loading or compressibility factor $\Psi$ versus partial pressure

The curves are obtained by integration of the isotherms using Equation 4, and illustrate the graphical meaning of the limit values $\mathrm{P}_{\text {lim }}$ and $\Psi_{\text {lim }}$ 


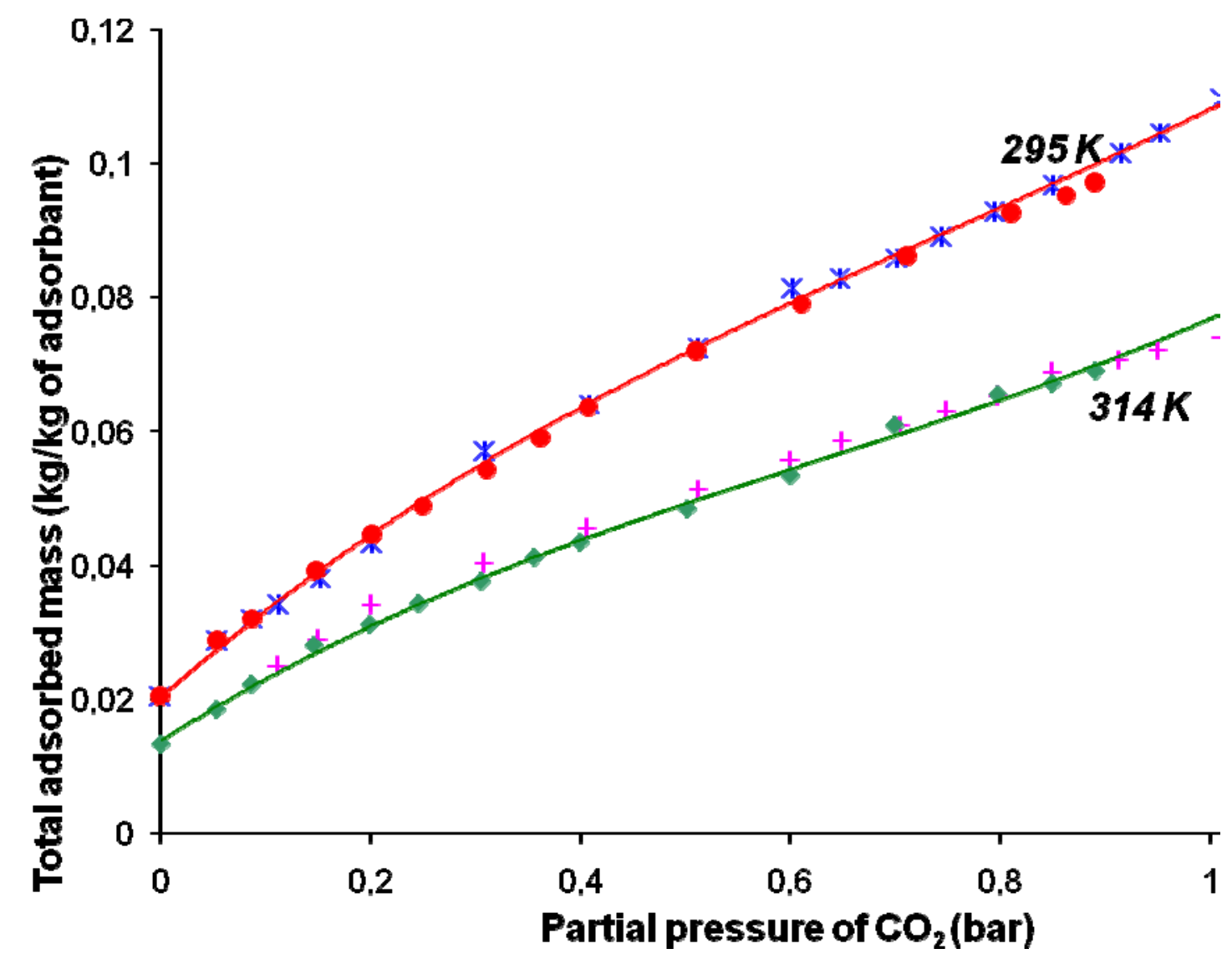

Figure 4 Total adsorbed mass ratio versus partial pressure at two temperatures

The ordinate is $m_{t} / m_{a}$, i.e. the value measured by the microbalance minus the mass of the clean adsorbent, divided by the mass of adsorbent $\left(\mathrm{m}_{\mathrm{a}}=0.96927 \mathrm{~g}\right)$

* + Experimental values at decreasing $\mathrm{CO} 2$ concentration

- $\downarrow$ Experimental values at increasing $\mathrm{CO} 2$ concentration Cubic polynomial fit 


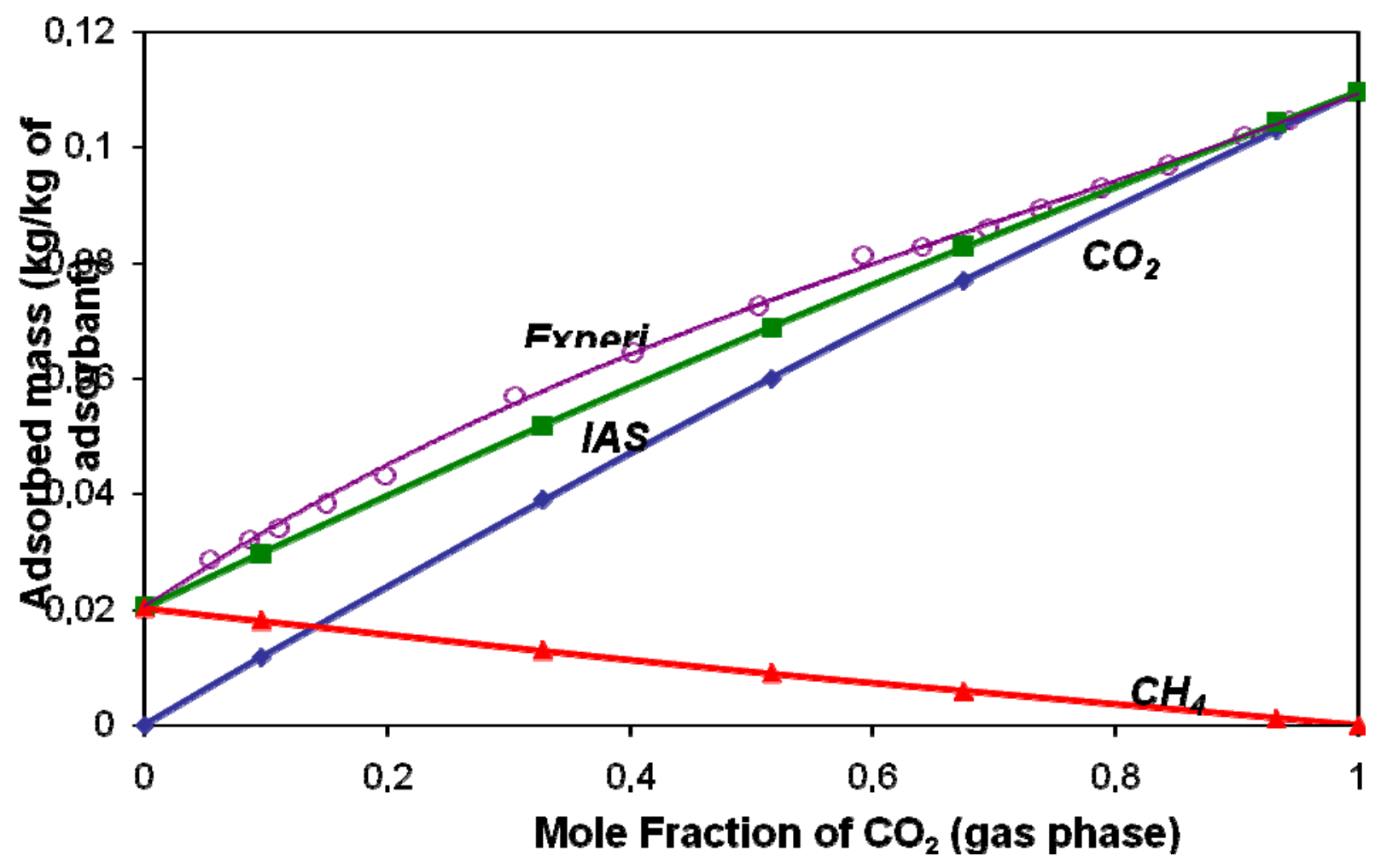

Figure 5 Binary isotherms at $295^{\circ} \mathrm{K}$ and 1.01 bar. IAS predictions and experiment

o Total adsorbed mass ratio measured (identical to that of Figure 4)

- Total adsorbed mass ratio calculated by the Ideal Adsorbed Solution (IAS) model

$\checkmark$, $\Delta$ Individual component adsorbed mass ratio calculated by the IAS model Graphical fit 


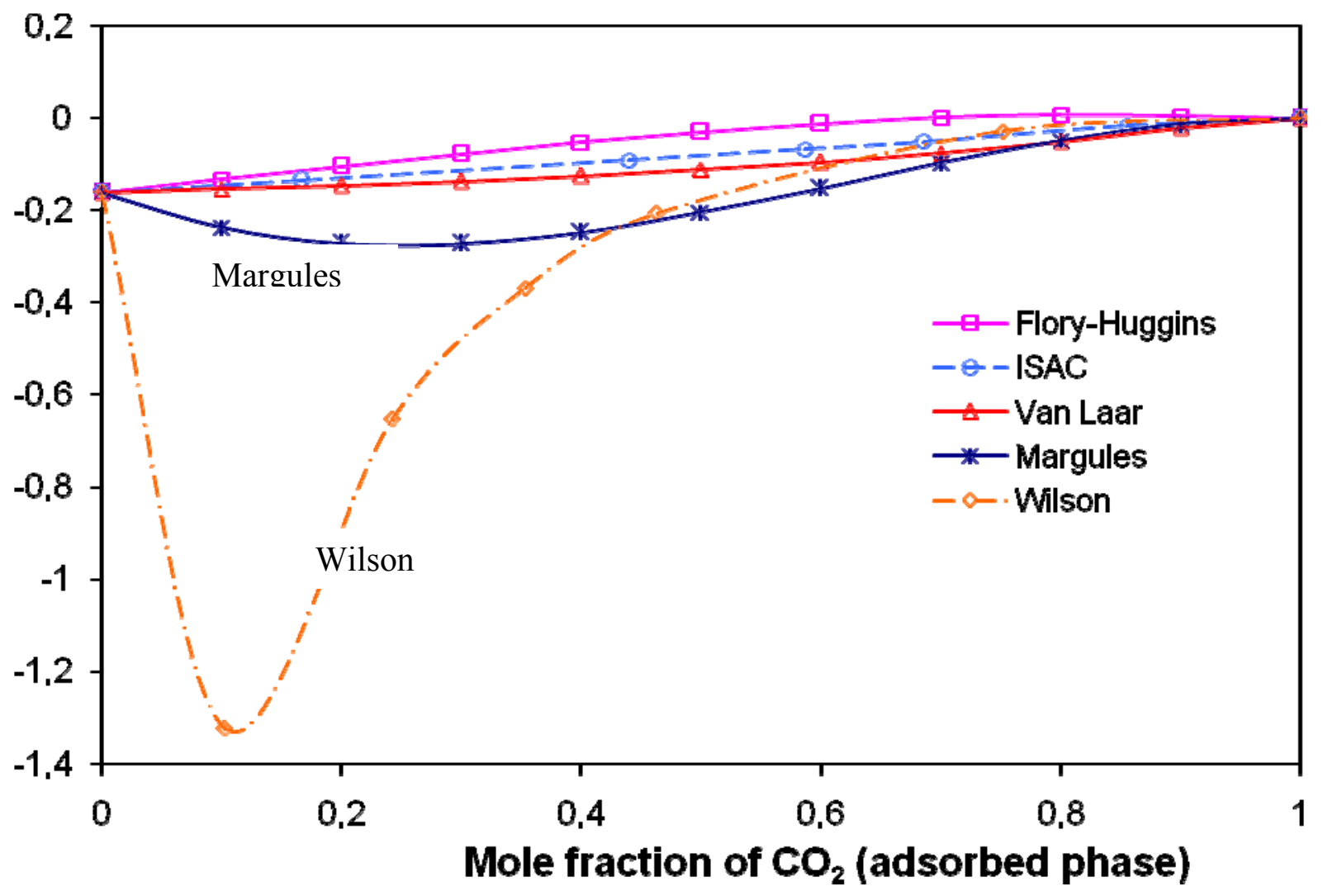

Figure 6a Variation of $\mathrm{CO} 2$ activity coefficients with binary composition for five models $\left(295^{\circ} \mathrm{K} ; 1.01 \mathrm{bar}\right)$. The ordinate scale is logarithmic 


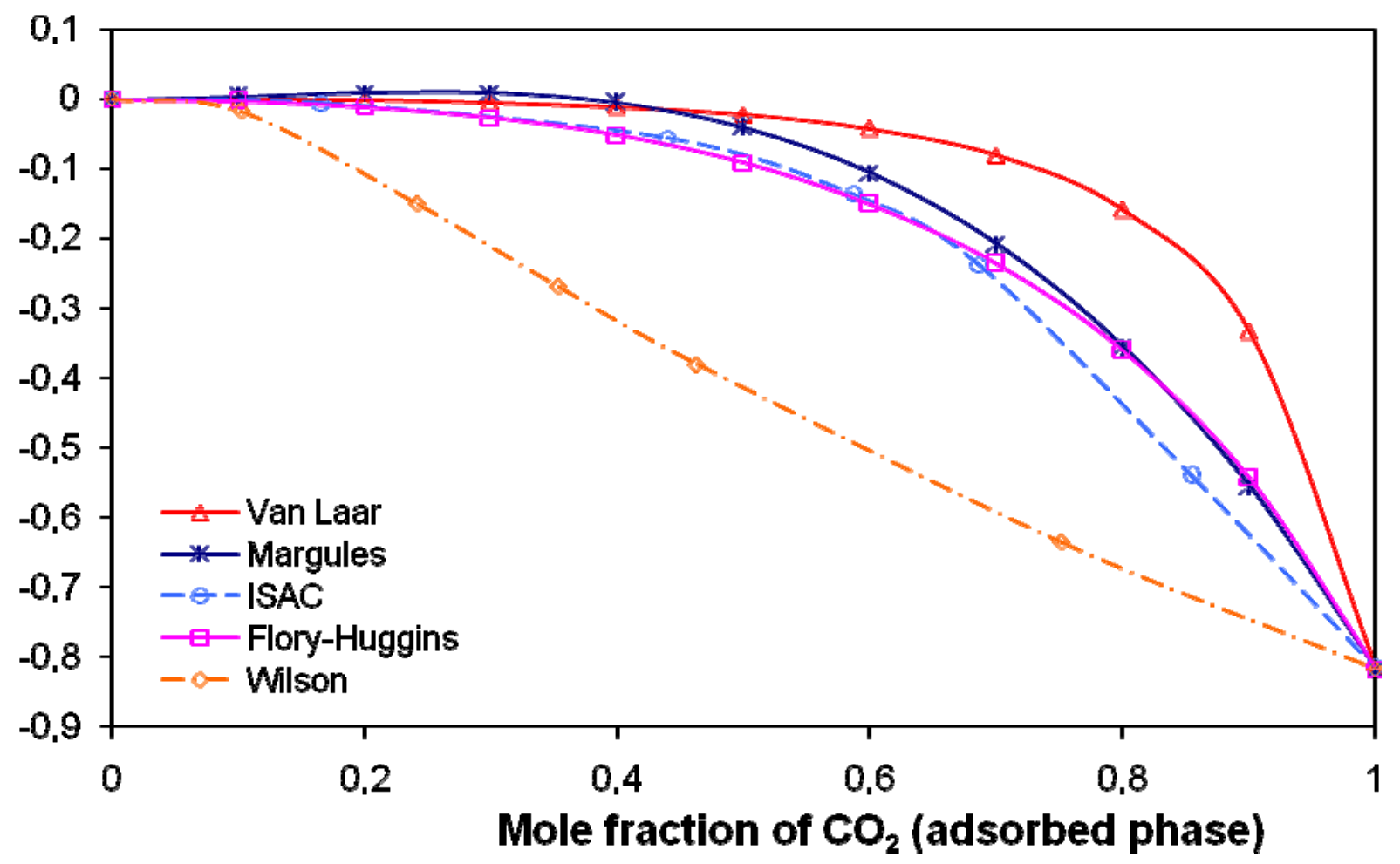

Figure $6 \mathrm{~b}$ Variation of $\mathrm{CH} 4$ activity coefficients with binary composition for five models $\left(295^{\circ} \mathrm{K} ; 1.01 \mathrm{bar}\right)$. The ordinate scale is logarithmic 


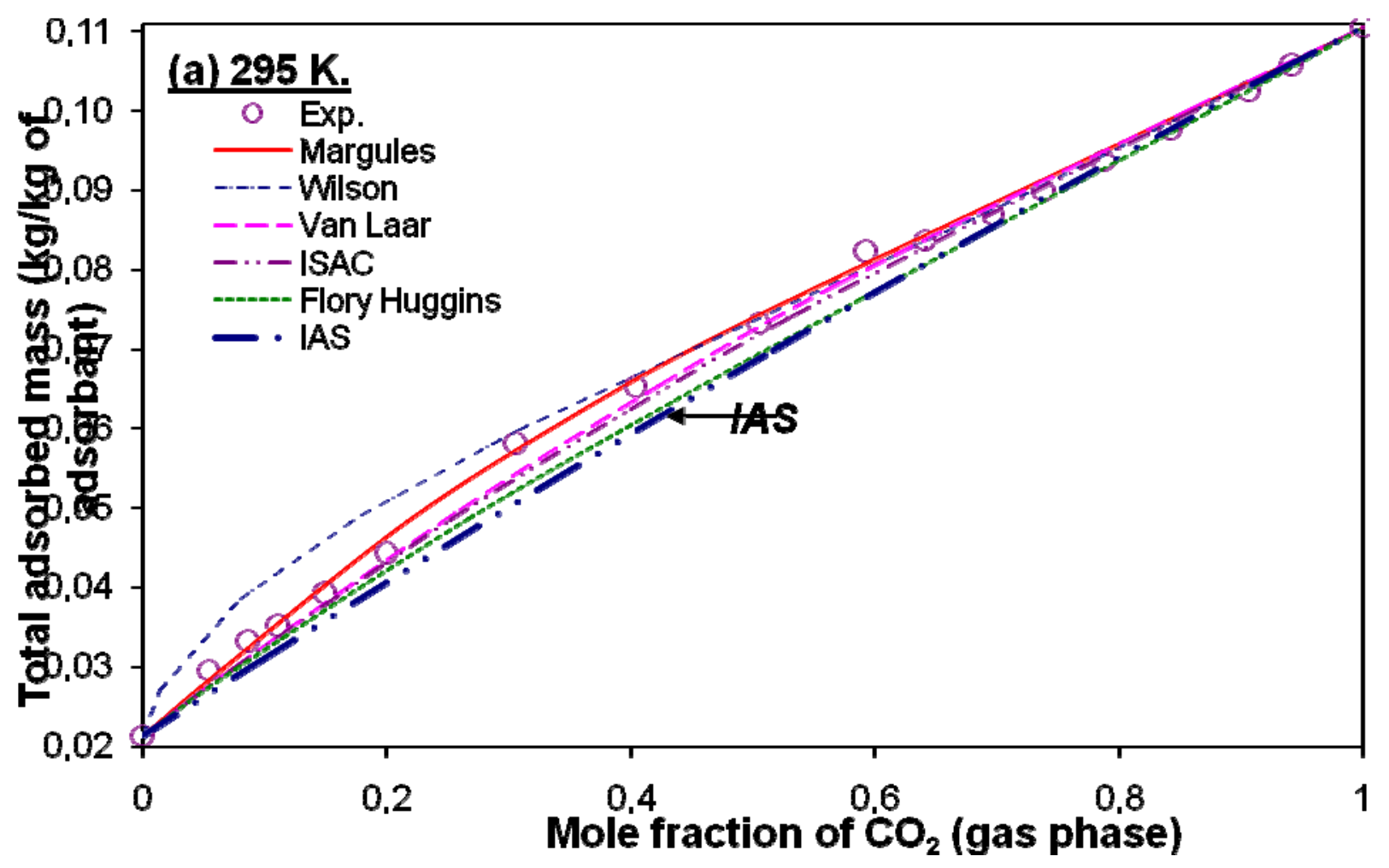

Figure 7a Comparison of the experimental total adsorbed mass ratio with the predictions of the ideal (IAS) model and with the five non-ideal models at $295^{\circ} \mathrm{K}$ 


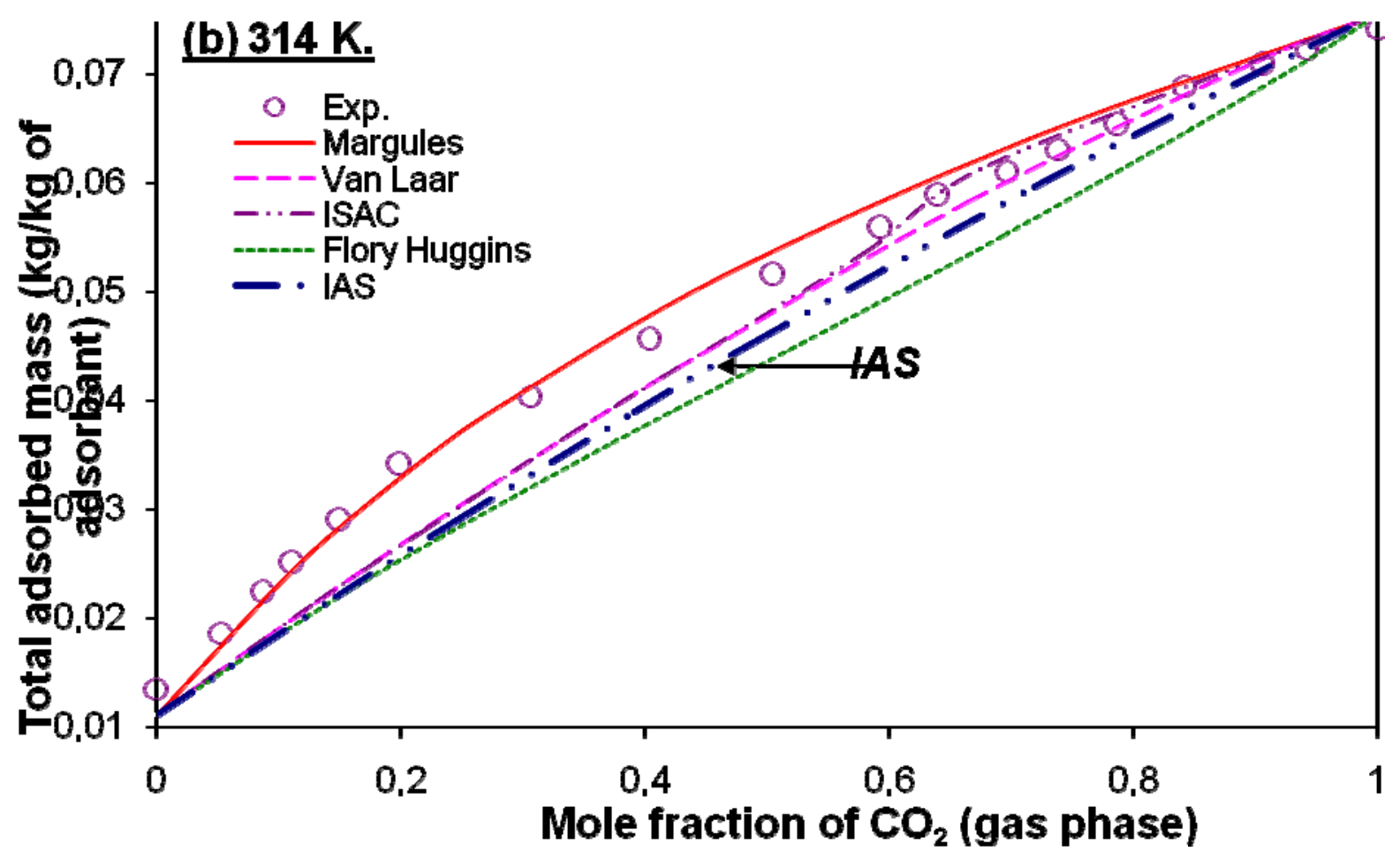

Figure $7 \mathrm{~b}$ Comparison of the experimental total adsorbed mass ratio with the predictions of the ideal (IAS) model and with the five non-ideal models at $314^{\circ} \mathrm{K}$ 


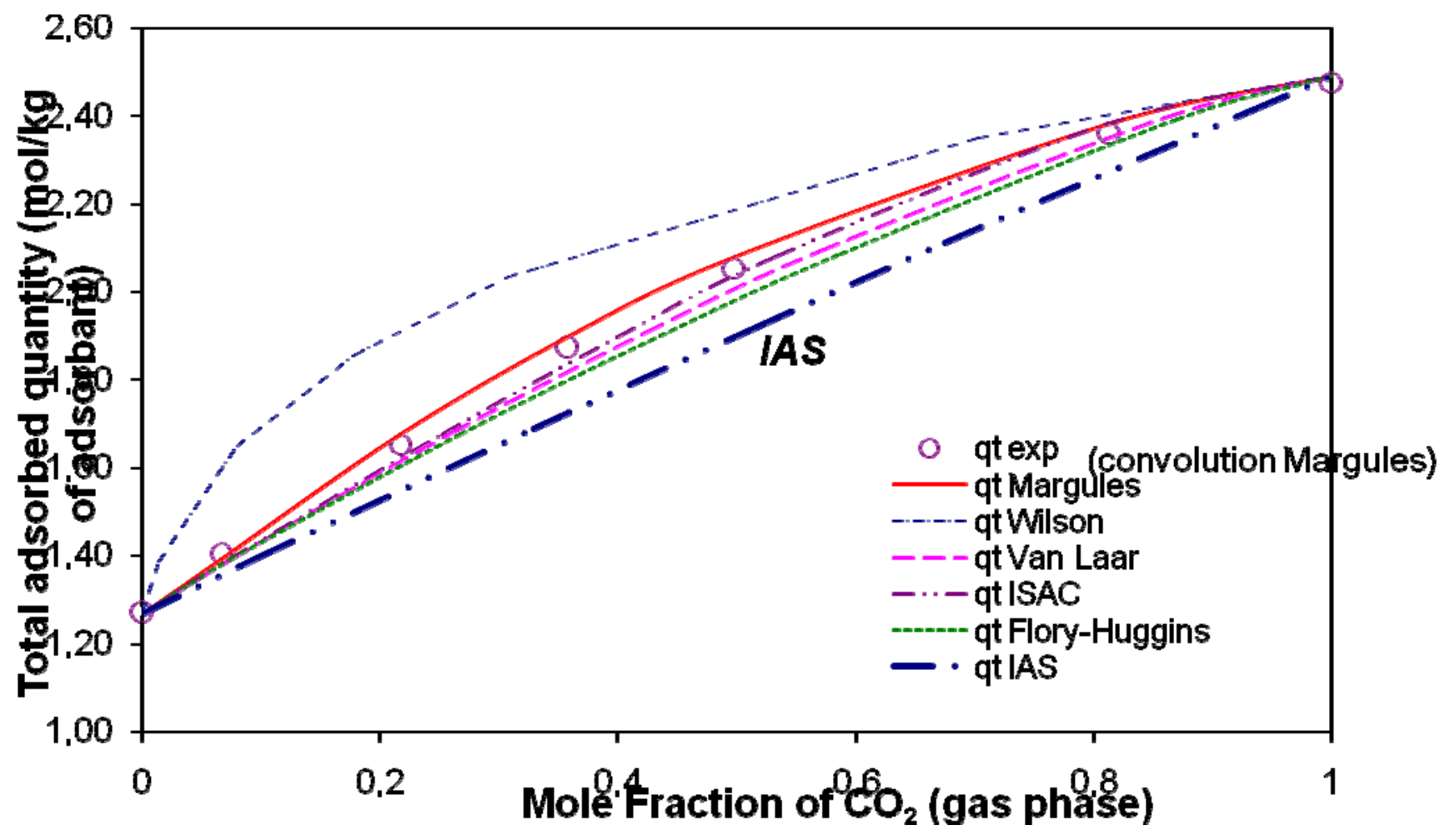

Figure 7c Comparison of the mole concentration in the adsorbed phase with the predictions of the ideal (IAS) model and with the five non-ideal models at $295^{\circ} \mathrm{K}$; 


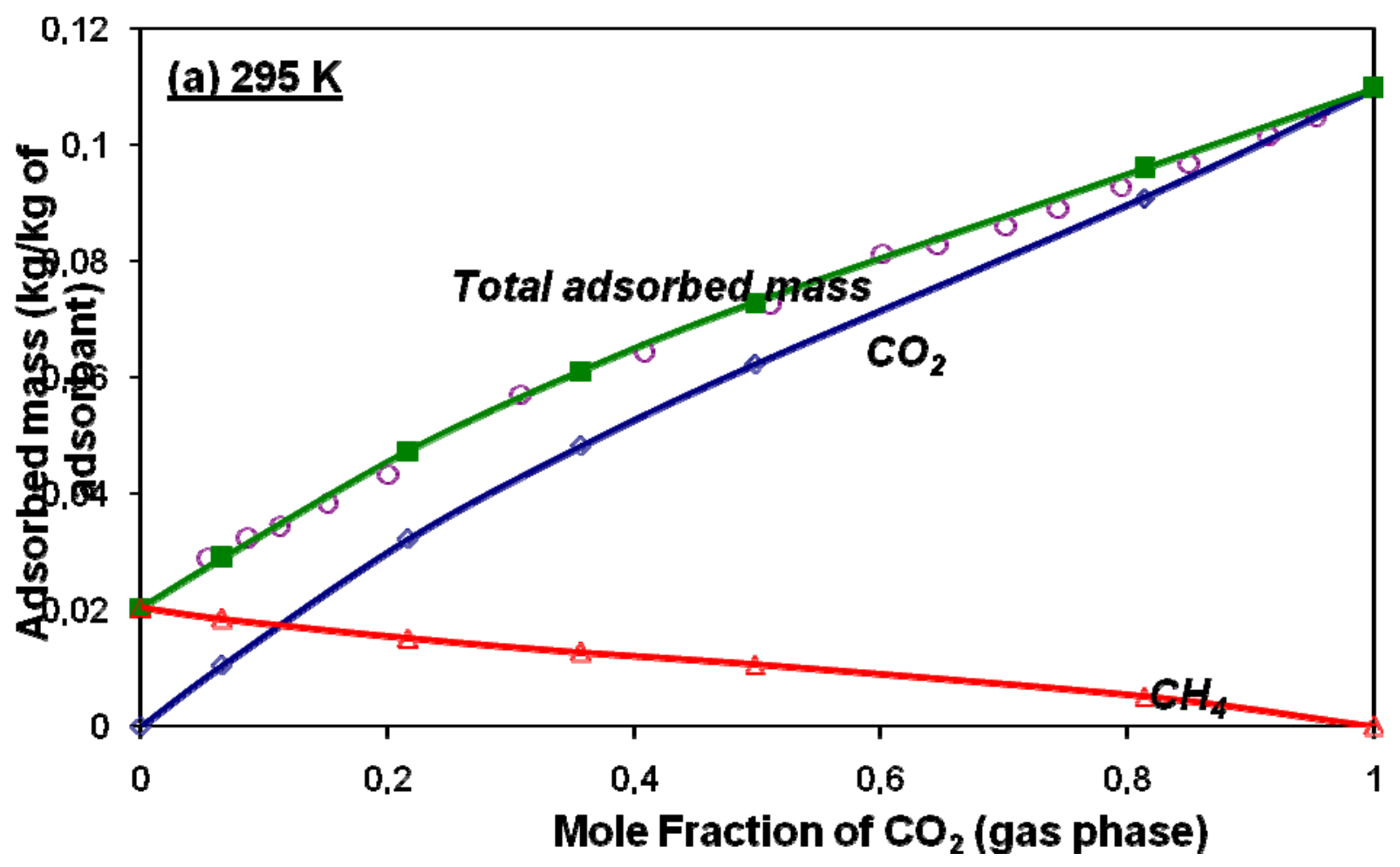

Figure 8a Binary adsorption isotherms described by the two-parameter Margules model at $295^{\circ} \mathrm{K}$

The Margules model is in Table 5 and the parameter values are in Table 6.

o Total adsorbed mass ratio, experimental values

- Total adsorbed mass ratio, calculated

$\diamond, \Delta \quad$ Individual components, calculated graphical fit 


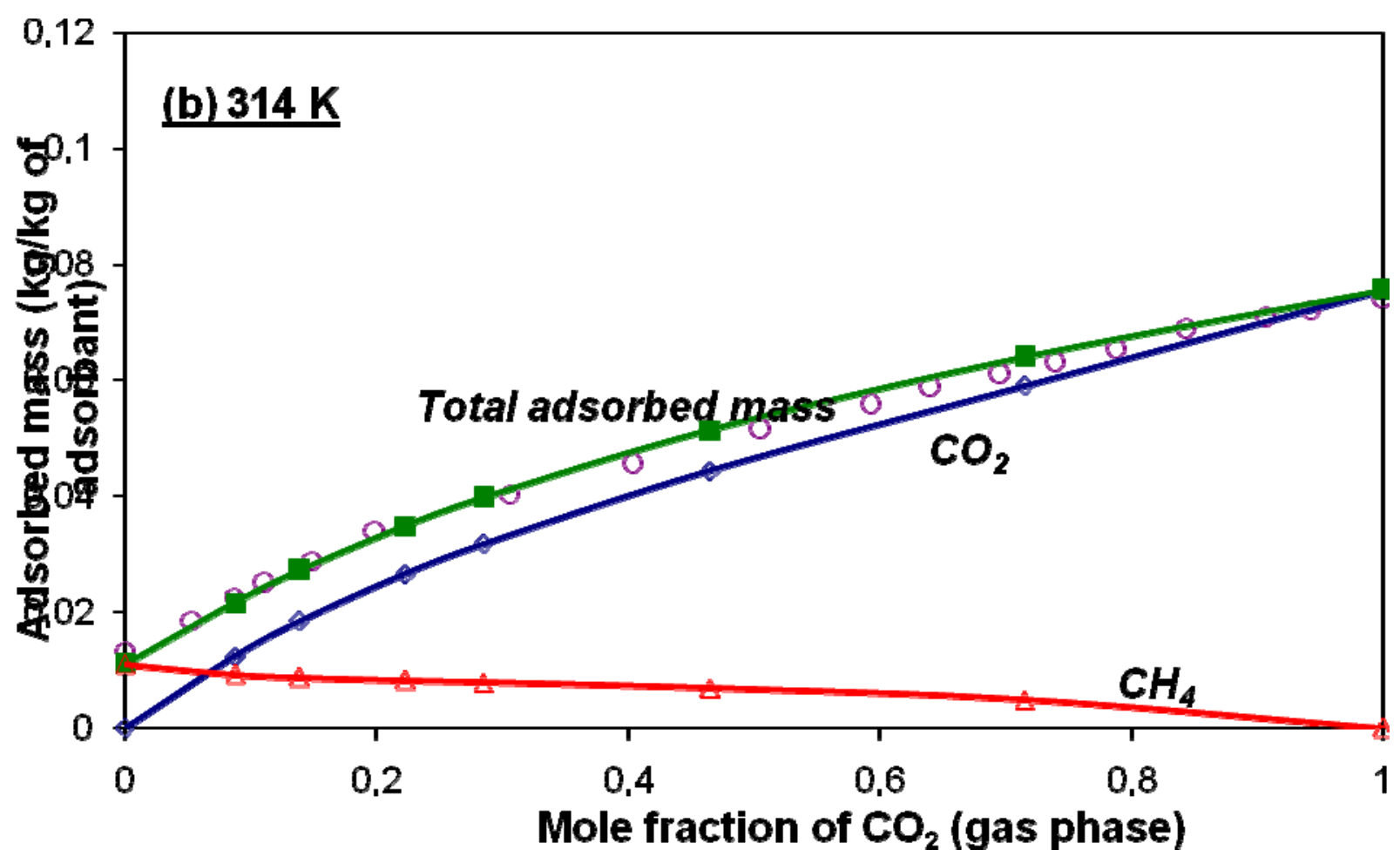

Figure $8 \mathrm{~b}$ Binary adsorption isotherms described by the two-parameter Margules model at $314^{\circ} \mathrm{K}$

The Margules model is in Table 5 and the parameter values are in Table 6.

o Total adsorbed mass ratio, experimental values

- Total adsorbed mass ratio, calculated

$\diamond, \Delta \quad$ Individual components, calculated graphical fit 


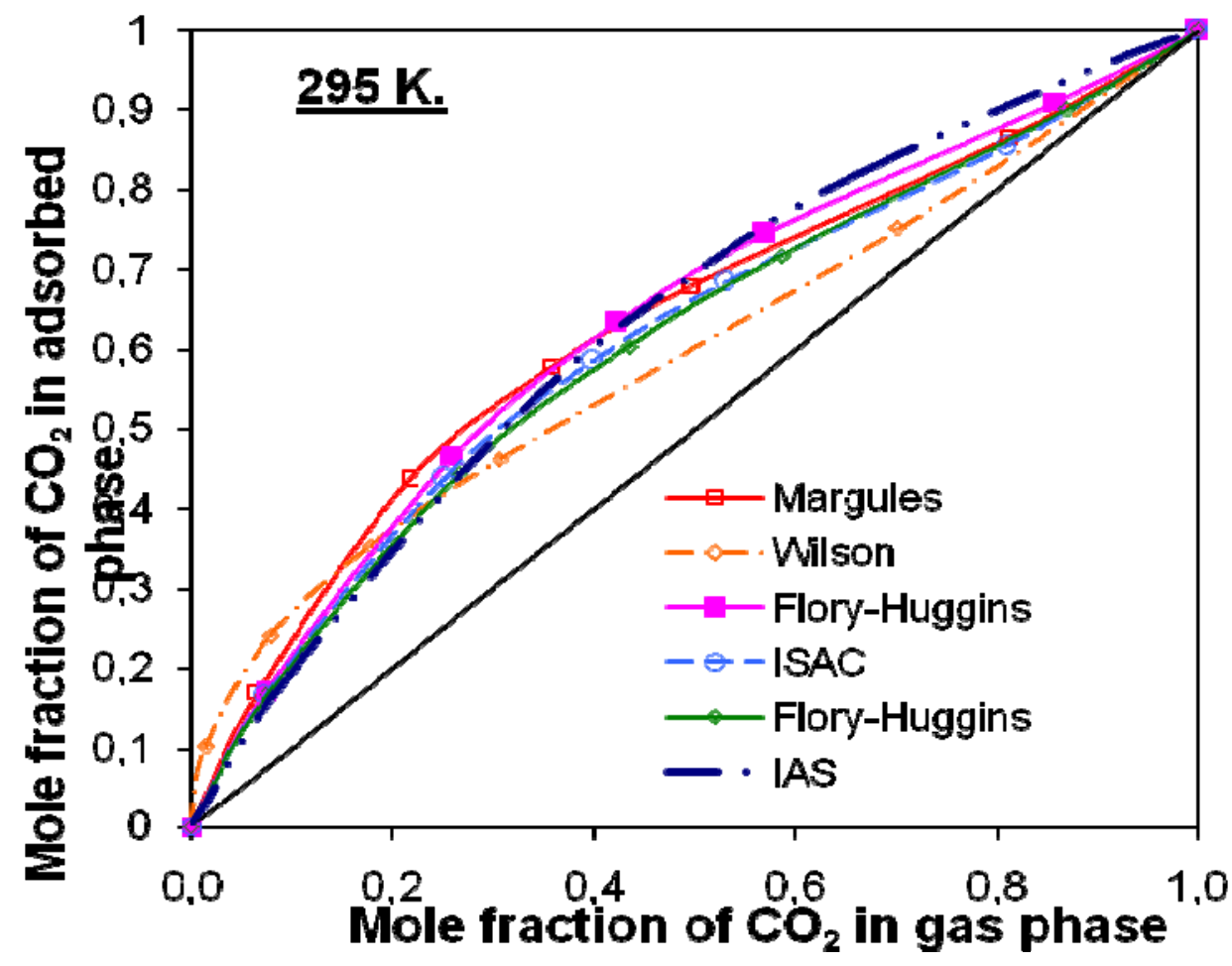

Figure 9 Phase diagram for $\mathrm{CO} 2$ calculated from experimental data using different models 


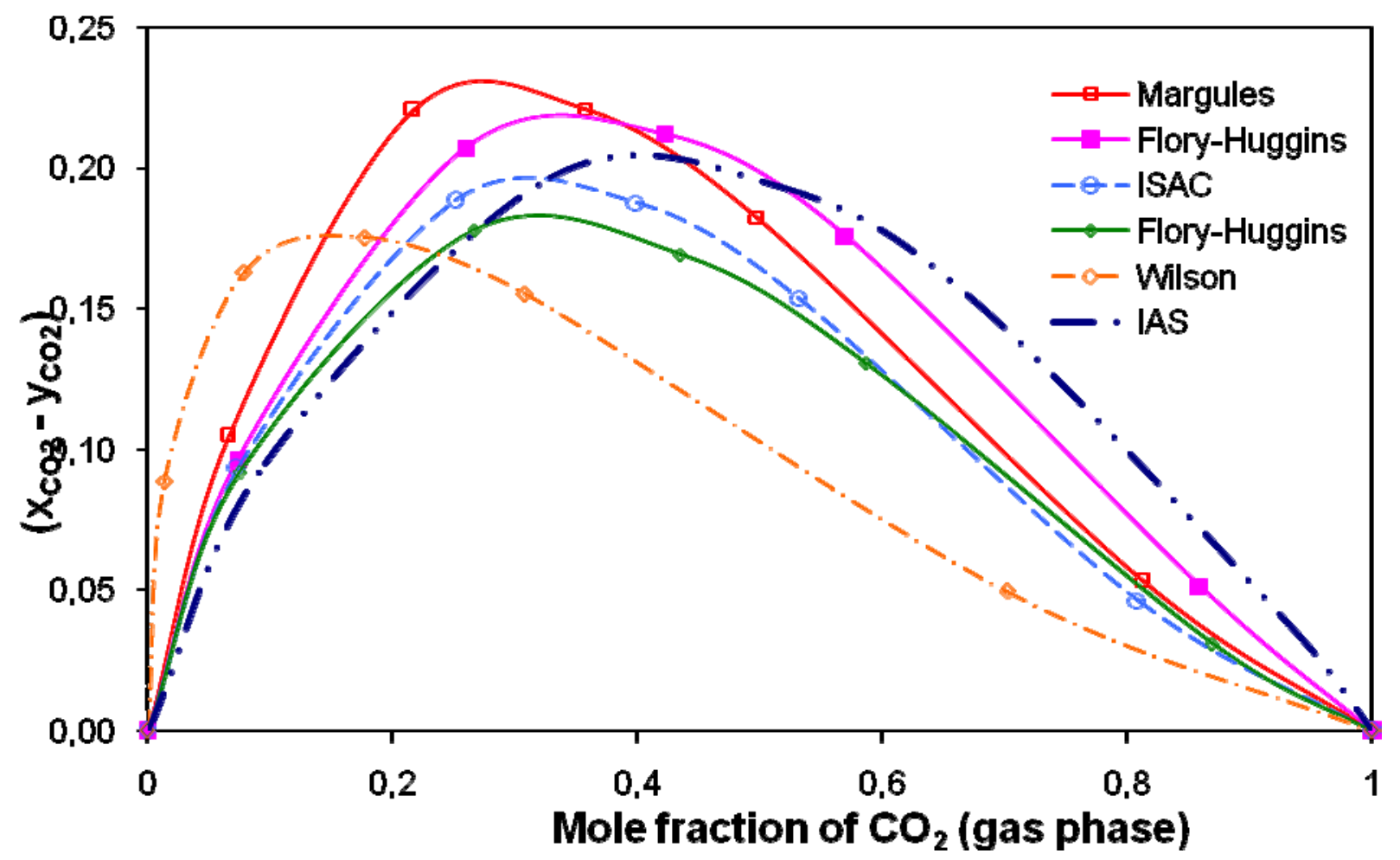

Figure 10 Difference phase diagram calculated from different models at $295^{\circ} \mathrm{K}$

The ordinate represents the difference between the adsorbed mole fraction $\mathrm{x}$ predicted from the models and the gas phase mole fraction $y$. 


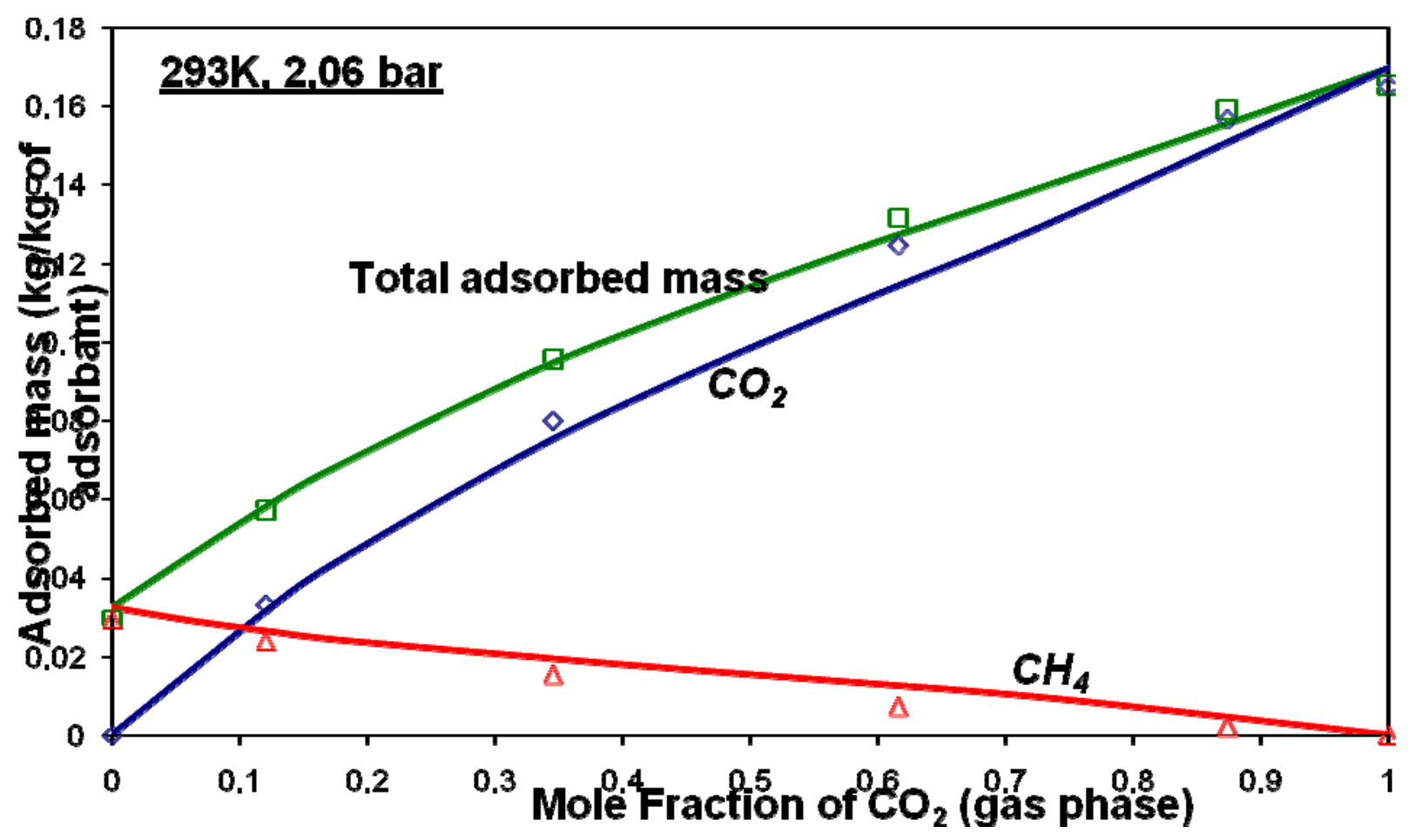

Figure 11 Binary isotherms at $293^{\circ} \mathrm{K}$ and 2.06 bar, predicted and experimental.

$\Delta \diamond \quad$ Measured mass concentrations of individual components

- Total mass adsorbed calculated as the sum of the individual components

Calculated curve using the single component isotherms of Figure 2 and the Margules model with the parameters at 2.06 bar (Table 8 ) 